\title{
Study on the Characteristics of Safety Distribution Changing with Buried Depth for Metro Station in Upper-Soft and Lower-Hard Stratum
}

\author{
Keguo Sun, Weiping Xu (D), Wenge Qiu, Haobo Li, Qingyu Xian, and Tao Li \\ Key Laboratory of Transportation Tunnel Engineering, Southwest Jiaotong University, Chengdu, China \\ Correspondence should be addressed to Weiping Xu; xwp@swjtu.edu.cn
}

Received 18 April 2018; Accepted 3 September 2018; Published 10 October 2018

Guest Editor: Yixian Wang

Copyright (c) 2018 Keguo Sun et al. This is an open access article distributed under the Creative Commons Attribution License, which permits unrestricted use, distribution, and reproduction in any medium, provided the original work is properly cited.

\begin{abstract}
The reasonable buried depth of metro station should be investigated for Qingdao with the upper-soft and lower-hard stratum. Strength reduction method has been utilized to study FOS of metro station under different buried depths. As the buried depth increases, the curve of FOS can be divided into three parts as the slowly changed part, the rapidly-increased part, and the gradually-decreased part. Taking FOS $=1$ as limitation, the formula of least rock cover thickness has been derived. Based upon the formula, the characteristics of safety distribution changing with buried depth for metro station which behaves as three zones $\left(D_{I}\right.$, E, $\mathrm{D}_{\mathrm{II}}$ ) have been discovered. Two typical metro stations have been used to verify the research results.
\end{abstract}

\section{Introduction}

Along with the Chinese urbanization process, subway has been widely constructed in big cities. Many subsurface metro stations have been carried out in cities, such as Qingdao [1], Chongqing [2], Dalian [3], etc. These tunnels have common characteristics such as large span, shallowly buried, and with complicated surrounding environment. For the geological conditions, the upper part is soil and strong-weathered layer, the strength of which is low and this layer is called the weak layer. Under the weak layer, the stratum becomes hard rapidly, the strength of which is high and this layer is often composed by middle or weakly weathered rock. Therefore, the stratum behaves as upper-soft and lower-hard. Under this geological condition, two types of problem often occurred during the construction. One type of problem is that the excavation method is overcautious when the tunnel is in hard rock, which will lower the efficiency. The other type of problem is the large deformation of surrounding environment when the tunnel is in soil or the juncture of soil and rock.

Many studies have been carried out on the stability of tunnels. The stability of circular tunnel has been studied at
Cambridge since 1970s by several scholars, for example, Atkinson and Cairncross [4], Mair [5], and Davis et al. [6]; subsequently, the stability of circular tunnel in drained condition has been researched by Muhlhaus [7] and Leca and Dormieux [8]. In 2010, full analytical solution for tunnel with arbitrary shape has been determined by Fraldi and Guarracino [9]. In recent decades, the numerical method has been widely used to analyze the stability problem of tunnel. Using FEM, the ground settlement caused by tunnel construction was predicted by Rowe and Kack [10]. Considering the tunnel's shape, Koutsabeloulis and Griffiths [11] studied the failure mechanism. Back analysis has been studied on the shallow tunnel using the elastoplastic numerical method, and a good agreement between the filed monitoring data and numerical results has been reached by Azevedo et al. [12] and Sun et al. [13].

In 1975, Zienkiewicz et al. [14] put forward the strength reduction method (SRM), which was adopted by Matsui and San [15], Zheng et al. [16, 17], Lin and Chen [18], Liu et al. [19], Yao et al. [20], and $\mathrm{Ma}$ et al. [21] to analyze the geotechnical engineering problem, especially the slope failure. Tunneling is a kind of geotechnical engineering; the potential failure position is not clear, but the failure 
mechanism is similar as slope. So, SRM could be used to analyze the stability of tunnel as well. During the analysis process, the shear strength will be reduced to total failure. The factor of safety (FOS) for tunnel and the critical failure surface could be obtained. Based on the plain strain model, Sloan and Assadi [22] have used SRM to investigate the cases for which the shear strength linearly changes with buried depth. With more efficiency, the nonlinear programming technique has been adopted to study this case by Lyamin and Sloan [23]. Zhang et al. [24] applied the strength reduction finite element method to analyze the stability of road tunnels and discussed the difference between plastic zone and stress reduction factor (SRF). Zheng et al. $[25,26]$ thought that SRM is a kind of numerical limit analysis method, which can be used to get not only the FOS and the limit loading but also the failure position and form.

Research has also been carried out for various stratums. For hard rock, Zhao et al. [27] have applied experiments to appreciate the nonlinear rheological behavior. For the upper-soft lower-hard stratum, Wang et al. [28] have analyzed the loosening pressure of large-span tunnel in the upper-soft and lower-hard stratum using the discrete element method. Wang et al. [29] have studied the relationship between the overburden versus span ratio and the displacement of ground surface in the upper-soft and lowerhard stratum using the finite element method and found that the stratum condition is a decisive factor for the undercut subway station with shallow overburden.

The stability of tunnel has been taken under serious consideration, and the SRM method has been used to evaluate it as well. In previous studies, the loosening pressure and the relationship of the overburden versus span ratio and the stability have been studied for the large-span tunnel in the upper-soft and lower-hard stratum. However, the reasonable buried depth has less been considered. In this paper, SRM and finite differential method (FDM) have been adopted to get the FOS of metro station in different deepness. By evaluating the FOS rule, the reasonable buried depth of metro station could be reached. The flow diagram as shown in Figure 1 describes the process to determine the reasonable depth of metro station. The field monitoring data prove the reasonability of this study, which can guide the design for similar project in the future.

\section{Strength Reduction Method (SRM)}

2.1. Constitutive Relation. Due to the high aspect ratio, the problem in this paper can be considered as a plain-strain one. The failure complies with the Mohr-Coulomb criterion which can be expressed as follows:

$$
\begin{aligned}
F= & \frac{1}{3} I_{1} \sin \varphi+\left(\cos \theta_{\sigma}-\frac{1}{\sqrt{3}} \sin \theta_{\sigma} \sin \varphi\right) \sqrt{J_{2}}-c \cos \varphi=0, \\
& -\frac{\pi}{6} \leq \theta_{\sigma} \leq \frac{\pi}{6},
\end{aligned}
$$

where $I_{1}$ is the first invariant of stress tensor. $J_{2}$ is the second invariant of deviator stress tensor. $c, \varphi$, and $\theta_{\sigma}$ are the cohesion, internal friction angle, and lode angle, respectively.
The principle for calculating FOS of tunnel using SRM is shown in Figure 2. During the computational process, a series of strength reduction factors (SRF) has been chosen to synchronously reduce the stratum's strength. The method has been shown as expressions (2) and (3):

$$
\begin{aligned}
c^{\prime} & =\frac{c}{\mathrm{SRF}}, \\
\varphi^{\prime} & =\tan ^{-1} \frac{\tan \varphi}{\operatorname{SRF}} .
\end{aligned}
$$

For the unlined tunnel, an initial value for SRF should be chosen first, which is usually a little more than 1 . If the unlined tunnel is stable, the SRF will be gradually increased to the total failure of the tunnel. If the unlined tunnel cannot be stable, another SRF should be set, which is usually a little more than 0 , such as 0.1 , and will increase gradually even to failure. Utilizing this method, a series of SRF can be obtained. By numerical computation, the displacement of key points for each SRF can be reached as well.

2.2. Failure Criteria. The SRM can be utilized for analyzing the stability of tunnel. However, the success of SRM is significantly depending on the definition of failure. Three criteria have been commonly utilized to define the failure of tunnel.

(1) Criterion I, the plastic zone runs through criterion. At failure, a band is formed within the surrounding rock, in which all elements are in plastic state and the band would extend through the surrounding rock. However, even in the plastic state, the surrounding rock still has bearing capacity as studied by Matsui and San [15] as well as Kanungo et al. [30].

(2) Criterion II, the nodal displacements increase significantly. The SRF before the displacement increasing obviously will be taken as the FOS. Zienkiewicz et al. [14], Griffiths, and Lane [31] have utilized this method to analyze the stability of slope.

(3) Criterion III is the computational divergent criterion. During the numerical process, a convergence result cannot be reached, which indicates that the model cannot reach a balance, namely, the tunnel is failed as studied by Zienkiewicz et al. [14] and Dawson et al. [32].

In this paper, the conjunction criterion of I and II has been adopted to analyze the failure of the tunnel. First, the plastic zone runs through totally. Then, the SRF when mutation of displacement occurs has been taken as FOS.

2.3. Displacement of Key Points. The difference between tunnel and slope is that the failure position for tunnel is not sure. The failure position for tunnel may be at the crown, the hance, or the spring of arch. Therefore, five investigation points (IPs) have been chosen, and the key point will be obtained from these points. The profile of tunnel and the IPs are shown in Figure 3. 


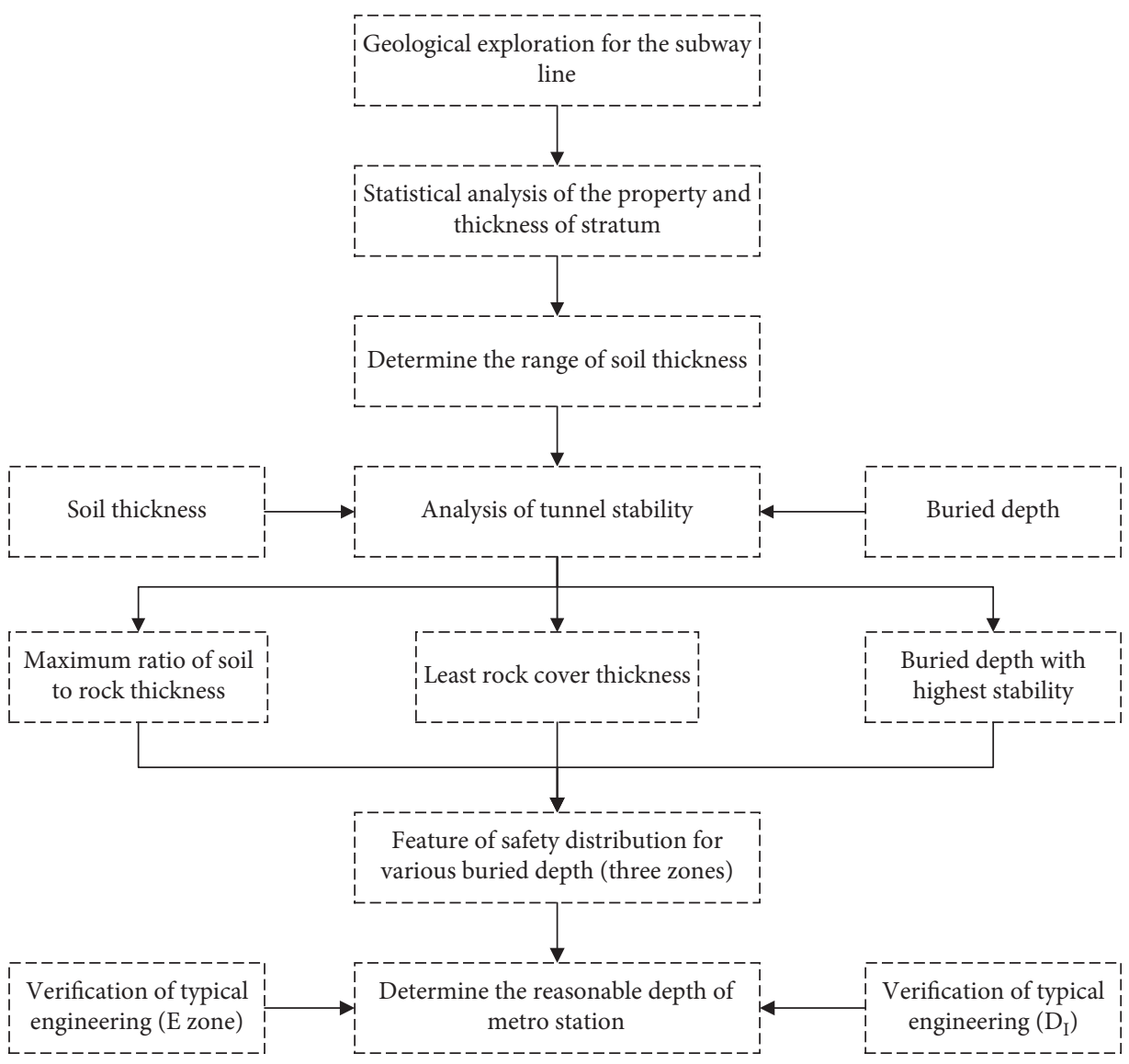

Figure 1: Process to determine the reasonable depth.

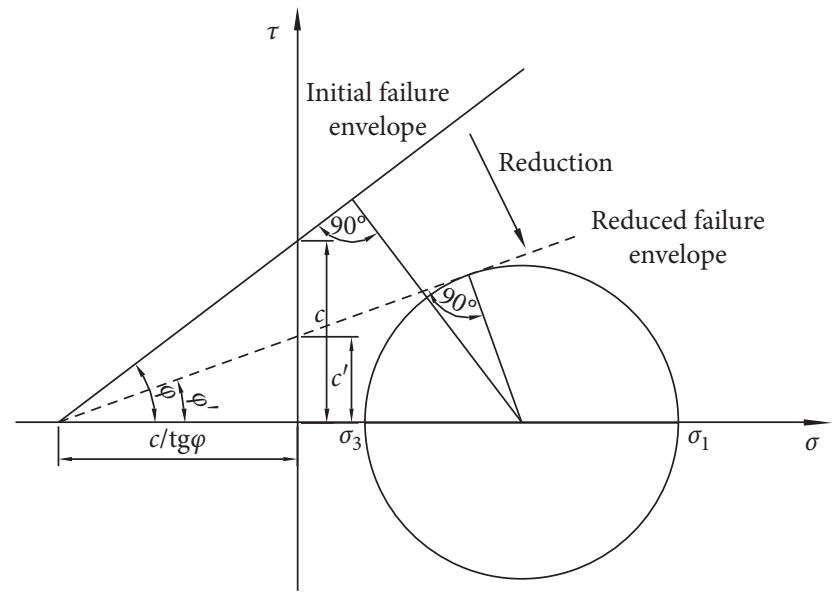

Figure 2: Mohr circle and failure envelope for the SRM.

2.4. Determination of FOS. By computation, the displacements of IPs can be reached for each SRF. In order to analyze the rule, the displacement curve of IP changing with SRF has been obtained. The displacement saltation can be evaluated utilizing the angle difference $\left(\theta_{i}\right)$ or slope ratio $\left(S_{\mathrm{r}}\right)$, as shown in expressions (4) and (5). The corresponding SRF will be treated as the FOS as shown in Figure 4. In this paper, the angle difference $\left(\theta_{i}\right)$ is adopted:

$$
\begin{aligned}
\theta_{i} & =\arctan \left(k_{i}\right)-\arctan \left(k_{i-1}\right), \\
S_{\mathrm{r}} & =\frac{k_{i}}{k_{i-1}} .
\end{aligned}
$$

\section{The FOS of Tunnel under Different Buried Depth in the Upper-Soft and Lower-Hard Stratum}

Under the influence of weathering or erosion, the compression strength of stratum near the surface is usually low. The stratum behaves as the soil characteristic. When the depth increases and the weathering condition weakens, the uniaxial compressive strength will increase, and the stratum presents as the rock property. Therefore, the thickness of the upper soil has an important influence on the building space of metro station in upper-soft and lower-hard stratum. However, the thickness of upper soil is very important to the metro, especially in Qingdao, Chongqing, Dalian, etc. Whether the buried depth of metro station is reasonable or not will influence and even determine the safety, time limit, and cost of the project.

The thickness of soil is distinct in different cities and various locations. In order to analyze the influence of soil thickness (ST) to the stability of tunnel, seven cases of ST 


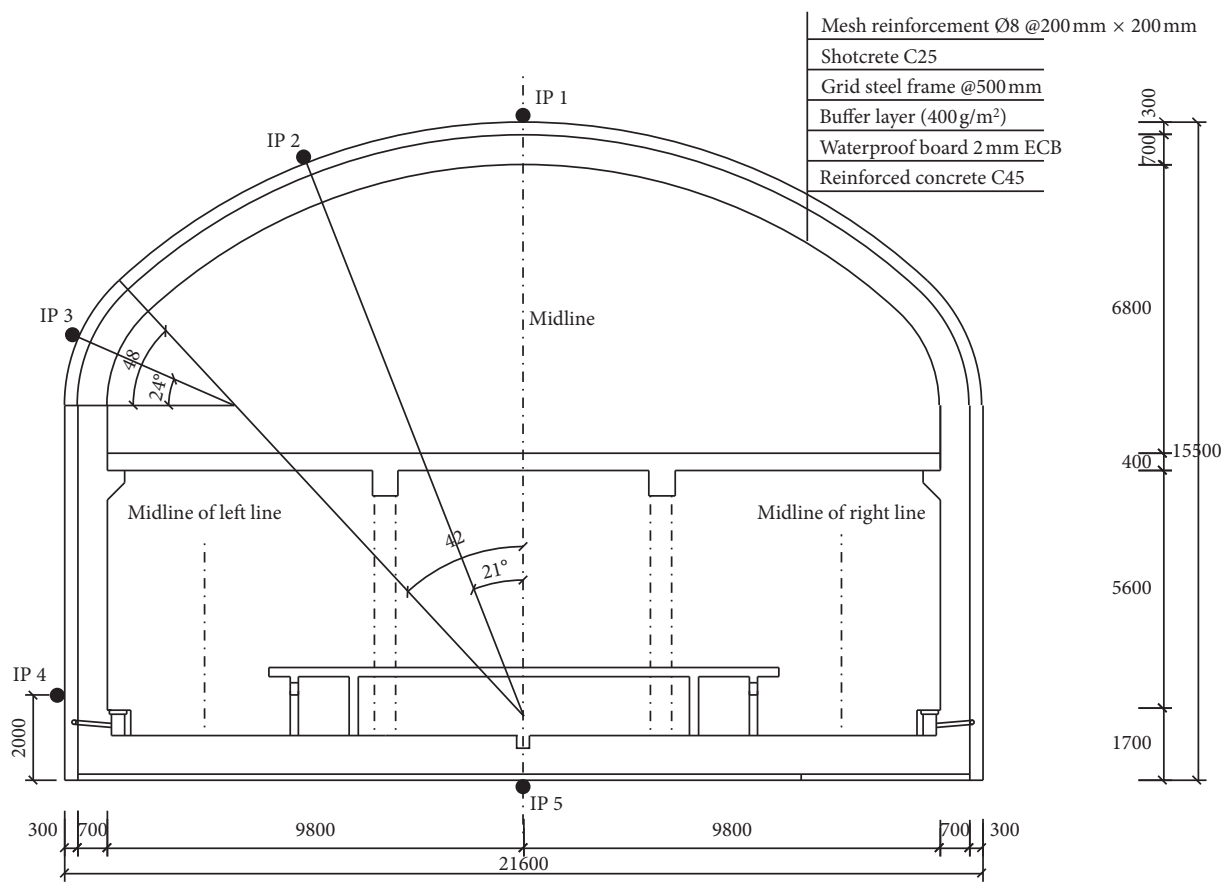

FIGURE 3: Section profile and arrangement of IPs.

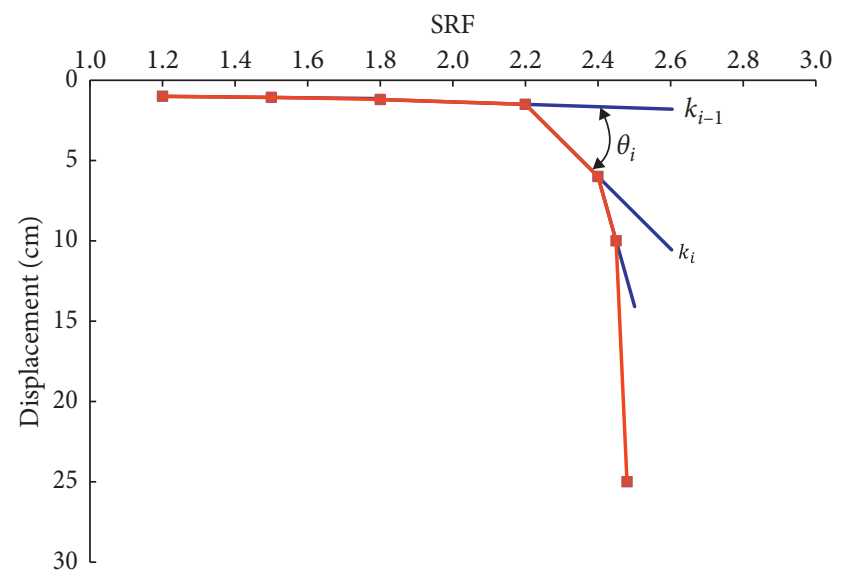

FIgURE 4: The scheme for determining the FOS.

have been studied, such as 6 meters, 9 meters, 12 meters, 18 meters, 24 meters, 36 meters, and 48 meters.

3.1. Introduction of Calculation Program. The Fast Lagrangian Analysis of Continua in 3 Dimensions method (FLAC3D) is used to simulate in the calculation. FLAC3D is a three-dimensional explicit finite difference program that can simulate the three-dimensional mechanical behaviors of rock and soil or other materials. The computational domain in FLAC3D is divided into many hexahedral elements, where each element in the given boundary conditions must follow specified linear or nonlinear constitutive relation. And if the material yielding or plastic deformation takes place under element stress, the element mesh can be deformed with the deformation of the material. This is called the Lagrange algorithm. The explicit finite difference scheme is used to solve the differential control equations in the study area, and with the mixed discrete element model, it can accurately simulate the yielding, plastic flow, softening, and large deformation of the material. Especially in the field of elastoplastic analysis, large deformation analysis, and simulation of construction process, it has unique advantages.

(1) The "mixed discrete method" is used to simulate plastic failure and plastic flow, which is more accurate and reasonable than the "discrete integration method" which is commonly used in the finite element method.

(2) Even if the simulated system is static, the dynamic motion equation is still adopted, which makes FLAC3D to have no numerical obstacles in simulating physical unstable process.

(3) The "explicit solution" scheme is adopted. Therefore, the time spent on solving the stress-strain relationship of the nonlinear problem is almost the same as on solving the linear constitutive relationship. Moreover, it does not need to store stiffness matrix, which means that the medium capacity memory can be used to solve the multi element structure. The simulation of large deformation problem hardly costs more time than the small deformation problem because there is no stiffness matrix to be modified.

In this paper, the Mohr-Coulomb elastoplastic criterion is used in the simulation. The yielding criterion is shown as follows:

$$
f^{\mathcal{s}}=\sigma_{1}-\sigma_{3} N_{\varphi}+2 c \sqrt{N_{\varphi}}=0
$$

where $N_{\varphi}=(1+\sin \varphi) /(1-\sin \varphi) ; c$ is the cohesive force; and $\varphi$ is the internal friction angle. 
After yielding, the deformation of the rock mass will be a composite result of elasticity and plasticity. In the course of any increasing stress, the strain of the rock mass is composed of two parts: elastic component and plastic component. Therefore,

$$
d \varepsilon_{i j}=\left(d \varepsilon_{i j}\right)_{e}+\left(d \varepsilon_{i j}\right)_{p}
$$

The elastic strain component is easy to be obtained, and the relationship between the plastic component and the plastic potential function $Q$ is as follows:

$$
\left(d \varepsilon_{i j}\right)_{p}=d \lambda \frac{\partial Q}{\partial \sigma_{i j}} .
$$

In FLAC3D, the shearing plastic flow and the pulling plastic flow are defined separately and corresponding to the different flow rules. The shearing plastic flow is corresponding to the nonassociated flow rule, and the potential function is as follows:

$$
Q^{s}=\sigma_{1}-\sigma_{3} N_{\psi},
$$

where $N_{\psi}=(1+\sin \psi) /(1-\sin \psi)$ and $\psi$ is the dilation angle.

The pulling plastic flow is corresponding to the associated flow rule, and the potential function is as follows:

$$
Q^{t}=\sigma_{3} \text {. }
$$

3.2. Computational Model. The general computational model is shown in Figure 5, where $H$ is the buried depth of metro station and $H_{\mathrm{s}}$ and $H_{\mathrm{r}}$ are the thickness of soil and rock, respectively. To get the rule of tunnel for FOS changing with buried depth, 25 cases have been determined for each $H_{\mathrm{s}}$ as shown in Table 1, the total number of cases is 175 . From this figure, two equations can be reached as $R_{\mathrm{sr}}=$ $H_{\mathrm{s}} / H_{\mathrm{r}}$ and $H=H_{\mathrm{s}}+H_{\mathrm{r}}$. When the free face of tunnel is partially or totally in the soil layer, the value of $H_{\mathrm{r}}$ is zero. Taking case 9 of $H_{\mathrm{s}}=12$ as example, the computational model has been shown as Figure 6, the numerical model includes 9862 nodes and 4792 zones. For the other cases, $H$ and $H_{\mathrm{s}}$ are fixed as Table 1 .

Considering the geological condition of Qingdao subway, in the computational process, the soil and strongweathered layer have been taken as the soil layer and the middle-weathered and slightly weathered layer have been treated as the rock layer. Since the underground water is not rich for this case, and this paper is focused on the stability of surrounding rock, water is neglected in this paper. The stratum parameters are shown in Table 2. The effect of shear dilatancy has not been considered in this paper.

3.3. General Law. When the tunnel is shallow, with the increasing SRF, the tunnel will reach a critical state. The shear strain increment of tunnel (case 3 with $H_{s}=6$ ) is shown in Figure 7. The collapse position of surrounding rock is at vault, and the mode is tensile damage. For the deep tunnel (case 19 with $H_{\mathrm{s}}=6$ ), the shear strain increment at the

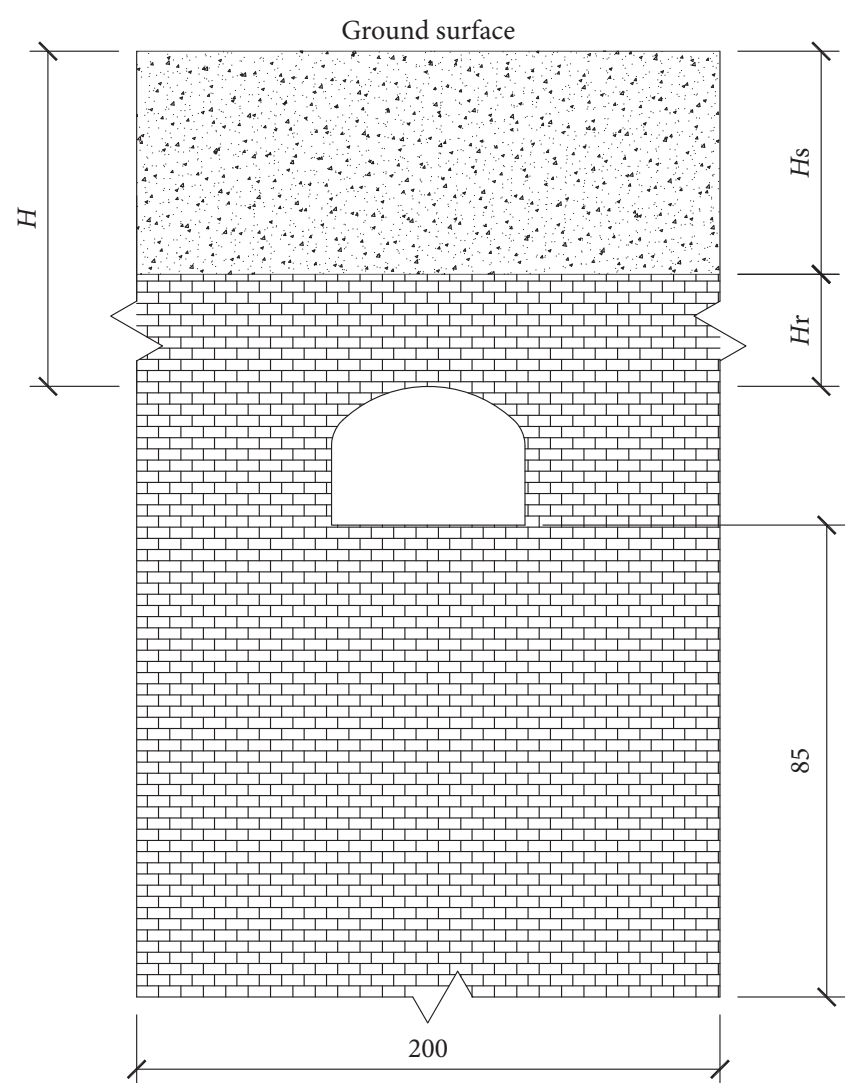

Figure 5: The general computational model.

critical state of stability is shown in Figure 8. The collapse location of surrounding rock is at the wall corner and the mode is shear damage. However, the displacement of vault will become large as well. The displacements of the five IPs have been analyzed for different cases as shown in Figure 9.

The displacement of the five IPs changing with SRF is shown in Figure 9. The displacements of IP1 and IP2 are negative, and suddenly change happens when the SRF equals to 0.895 . The displacements of IP3, IP4, and IP5 are positive, and suddenly change happens when the SRF equals to 0.895 . Since the five IPs have almost the same sensitivity, IP1 has been chosen as the target point.

3.4. Influence of Soil Thickness. For different ST, the FOS of metro station under various buried depth has been calculated. From this data, the curve of FOS changing with buried depth for different ST can be obtained. The curve is shown in Figure 10.

From Figure 10, several rules can be obtained. First, with the increasing of buried depth, the curve of FOS can be divided into three sections: slowly changed section, rapidly increased section, and gradually decreased section. The curve is nonlinear and nonmonotonic, and it generally presents a tendency to increase first and then decrease. Second, ST significantly affects the FOS, and when tunnel enters into the rock layer, the FOS will increase rapidly to a peak. Third, when the tunnel is in soil layer, FOS varies 
TABLE 1: Buried depth of metro station for each $H_{s}$.

\begin{tabular}{|c|c|c|c|c|c|c|c|}
\hline \multirow{2}{*}{ Order number } & \multicolumn{7}{|c|}{ Buried depth $H(m)$} \\
\hline & $H_{\mathrm{s}}=6$ & $H_{\mathrm{s}}=9$ & $H_{\mathrm{s}}=12$ & $H_{\mathrm{s}}=18$ & $H_{\mathrm{s}}=24$ & $H_{\mathrm{s}}=36$ & $H_{\mathrm{s}}=48$ \\
\hline 1 & 2 & 2 & 2 & 2 & 2 & 2 & 2 \\
\hline 2 & 4 & 4 & 4 & 4 & 4 & 4 & 4 \\
\hline 3 & 5 & 6 & 6 & 6 & 6 & 6 & 8 \\
\hline 4 & 6.25 & 8 & 8 & 8 & 10 & 10 & 12 \\
\hline 5 & 6.5 & 9.25 & 10 & 10 & 14 & 14 & 18 \\
\hline 6 & 6.75 & 9.5 & 12.25 & 15 & 18 & 18 & 24 \\
\hline 7 & 7.0 & 10.0 & 12.5 & 18.5 & 22 & 24 & 30 \\
\hline 8 & 8.0 & 12.0 & 14.0 & 19.0 & 24.5 & 30 & 36 \\
\hline 9 & 10.0 & 14.0 & 16.0 & 20.0 & 25.0 & 34 & 42 \\
\hline 10 & 12.0 & 16.0 & 18.0 & 22.0 & 26.0 & 37.0 & 46 \\
\hline 11 & 14.0 & 18.0 & 20.0 & 24.0 & 28.0 & 38.0 & 49 \\
\hline 12 & 16.0 & 20.0 & 22.0 & 26.0 & 30.0 & 41.0 & 50.0 \\
\hline 13 & 18.0 & 22.0 & 24.0 & 30.0 & 35.0 & 43.0 & 55.0 \\
\hline 14 & 20.0 & 24.0 & 26.0 & 32.0 & 40.0 & 50.0 & 60.0 \\
\hline 15 & 30.0 & 26.0 & 28.0 & 35.0 & 45.0 & 55.0 & 65.0 \\
\hline 16 & 50.0 & 28.0 & 50.0 & 40.0 & 50.0 & 60.0 & 70.0 \\
\hline 17 & 80.0 & 50.0 & 80.0 & 60.0 & 55.0 & 65.0 & 80.0 \\
\hline 18 & 100.0 & 100.0 & 100.0 & 100.0 & 100.0 & 100.0 & 100.0 \\
\hline 19 & 150.0 & 150.0 & 150.0 & 150.0 & 150.0 & 150.0 & 150.0 \\
\hline 20 & 200 & 200 & 200 & 200 & 200 & 200 & 200 \\
\hline 21 & 300 & 300 & 300 & 300 & 300 & 300 & 300 \\
\hline 22 & 400 & 400 & 400 & 400 & 400 & 400 & 400 \\
\hline 23 & 500 & 500 & 500 & 500 & 500 & 500 & 500 \\
\hline 24 & 600 & 600 & 600 & 600 & 600 & 600 & 600 \\
\hline 25 & 800 & 800 & 800 & 800 & 800 & 800 & 800 \\
\hline
\end{tabular}

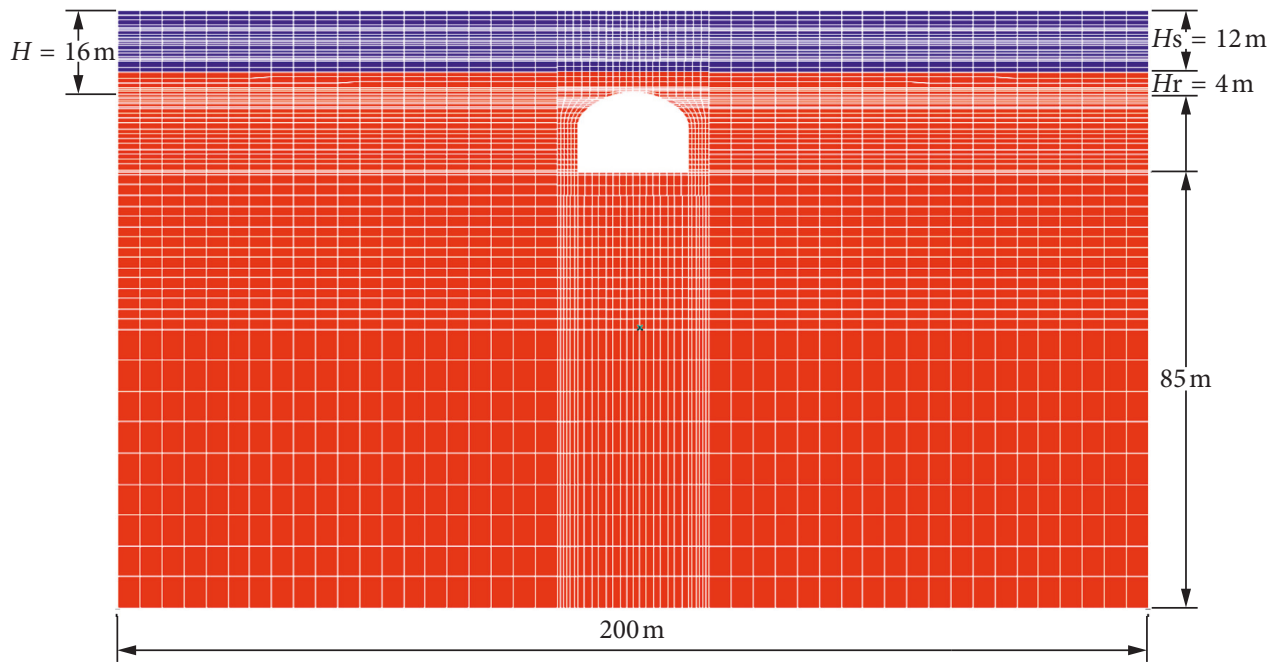

Figure 6: The computational model of Case 9.

TABLe 2: Computational parameters.

\begin{tabular}{lccccc}
\hline Stratum type & Unit weight $\left(\mathrm{kN} / \mathrm{m}^{3}\right)$ & Elastic module $(\mathrm{GPa})$ & Poisson ratio & Cohesion $(\mathrm{MPa})$ & Internal friction angle $\left(^{\circ}\right)$ \\
\hline Soil layer & 22.5 & 0.05 & 0.38 & 0.032 & 20 \\
Rock layer & 24.5 & 5.0 & 0.25 & 0.60 & 35 \\
\hline
\end{tabular}

very small and the value of FOS is far less than 1. Fourth, in general, FOS decreases when ST increases and the greatest value of FOS decreases as well. Last, when the buried depth of tunnel is over 200 meters, FOS is same for all ST under the identical buried depth. When the buried depth of tunnel exceeds certain depth, the influence of ST will disappear. 


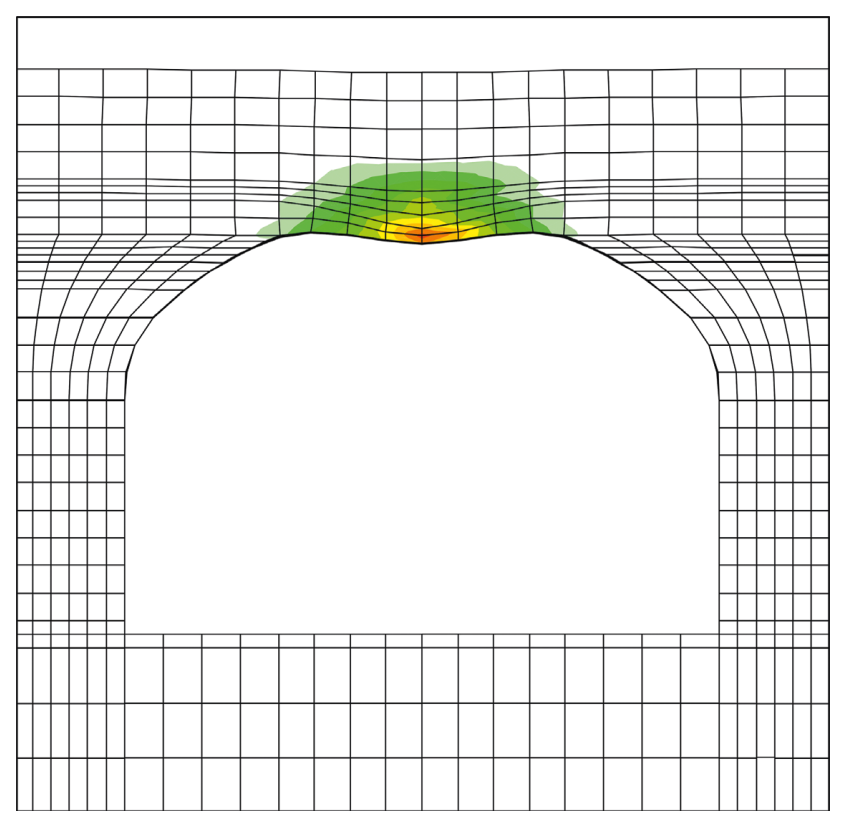

FIgURE 7: The shear strain increment of tunnel in case 3 with $H_{\mathrm{s}}=6$.

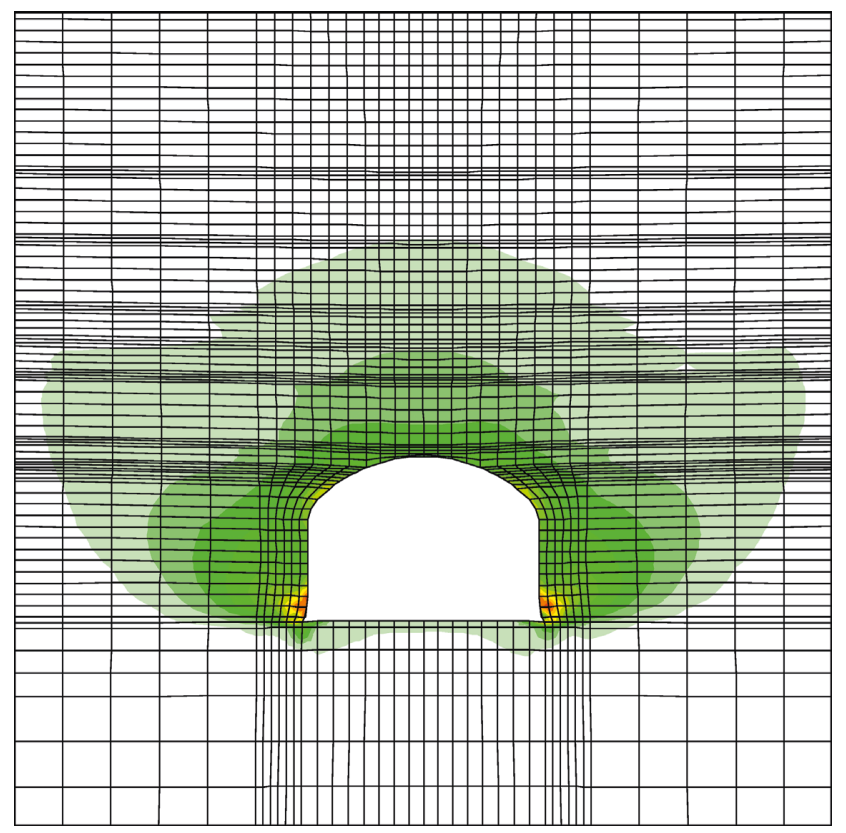

FIgURE 8: The shear strain increment of tunnel in case 19 with $H_{\mathrm{s}}=6$.

FOS increases rapidly when the tunnel is in rock layer, and to study the rule clearly, the part of curve near the interface has been cut out as shown in Figure 11.

When tunnel enters from soil into rock layer, the curve of FOS changing with $\mathrm{BD}$ is nearly linear. Therefore, the buried depth of tunnel for FOS = 1 can be reached, and the relationship of least rock cover thickness (LRCT) and ST and the relationship of the maximum ratio of soil to rock thickness (MRSR) and ST can be obtained, which is shown in Figures 12 and 13, respectively.

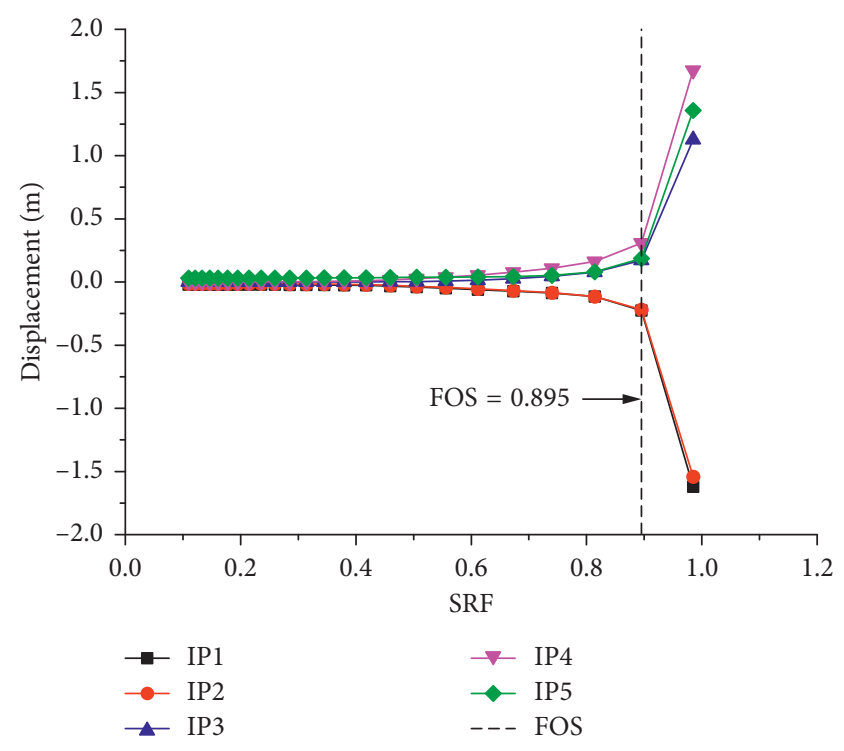

FIgURE 9: The displacements of the five IPs.

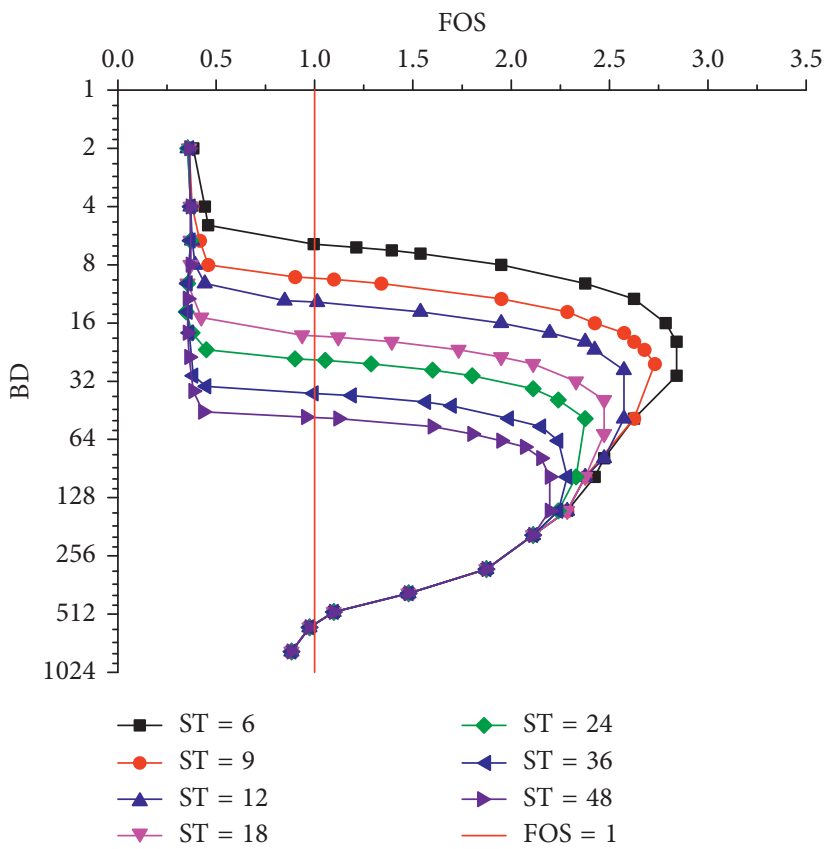

Figure 10: The relationship between FOS and BD.

As shown in Figure 12, the LRCT is enlarging with the increasing ST. The relationship between LRCT and ST is nearly linear. Therefore, a linear fitting has been utilized to predict LRCT as shown in Formula (11). The R-square of linear fitting is 0.975 which proves that the formula is reasonable. Using this formula, LRCT for different ST can be obtained.

$$
\mathrm{LRCT}=0.02345 \times \mathrm{ST}+0.18711 .
$$

From Figure 13, MRSR increases when ST grows. The relationship of MRSR and ST is nearly linear too, so a linear fitting can be used to predict MRSR under various ST. The 


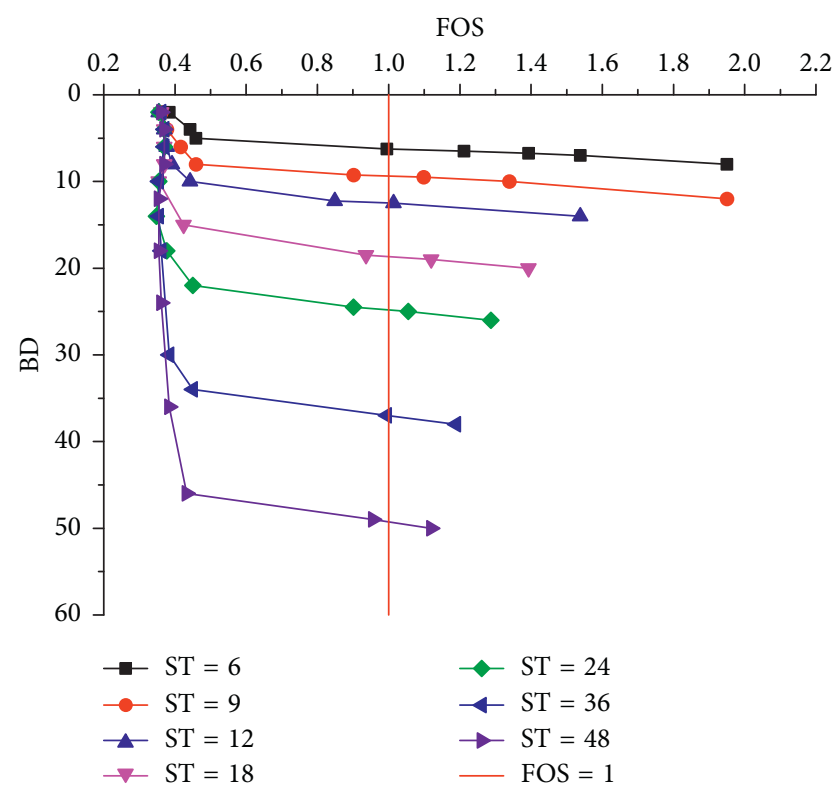

FIgURE 11: The relationship between FOS and $\mathrm{BD}$ (near the interface).

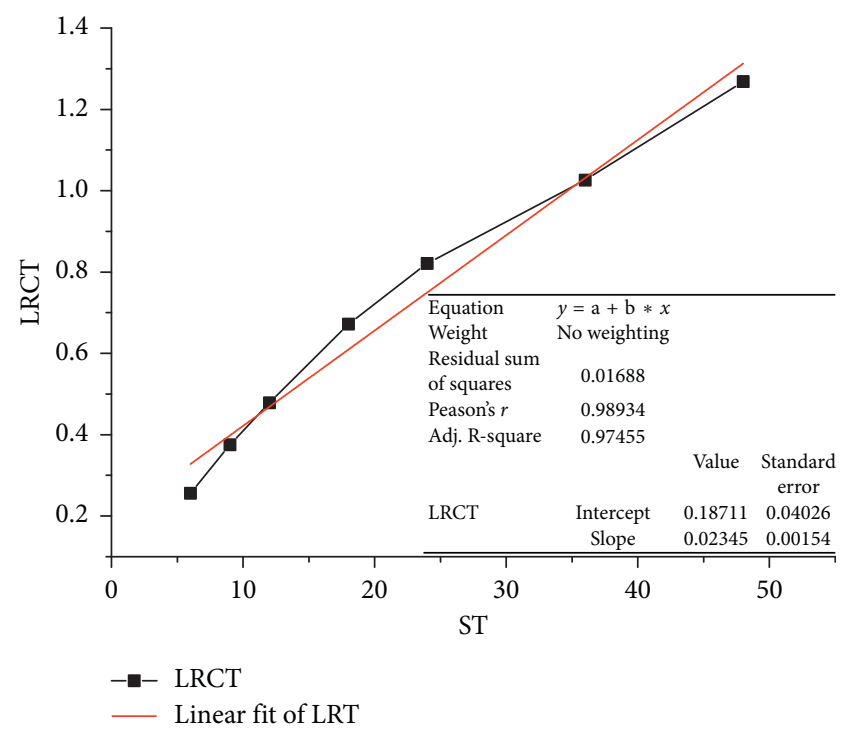

FIgURE 12: The relationship between LRCT and ST.

prediction formula has been shown in Formula (12), and the $R$-square is 0.986 which proves the validity of the formula.

$$
\mathrm{MRSR}=0.36557 * \mathrm{ST}+20.78412 .
$$

When ST varies between 6 and 48 meters, the precision of prediction can be guaranteed. If ST is not in this interval, the prediction should be studied further. In the view of geological condition and current situation of exploitation depth in Qingdao et al., the interval of 6 to 48 meters is enough; therefore, the prediction formula is preferable for determining the buried depth of metro station in Qingdao.

From Figure 10, for any BD, FOS will reach a maximum value under certain depth, which means the safety storage of tunnel reaches a peak. The rule of several indicators

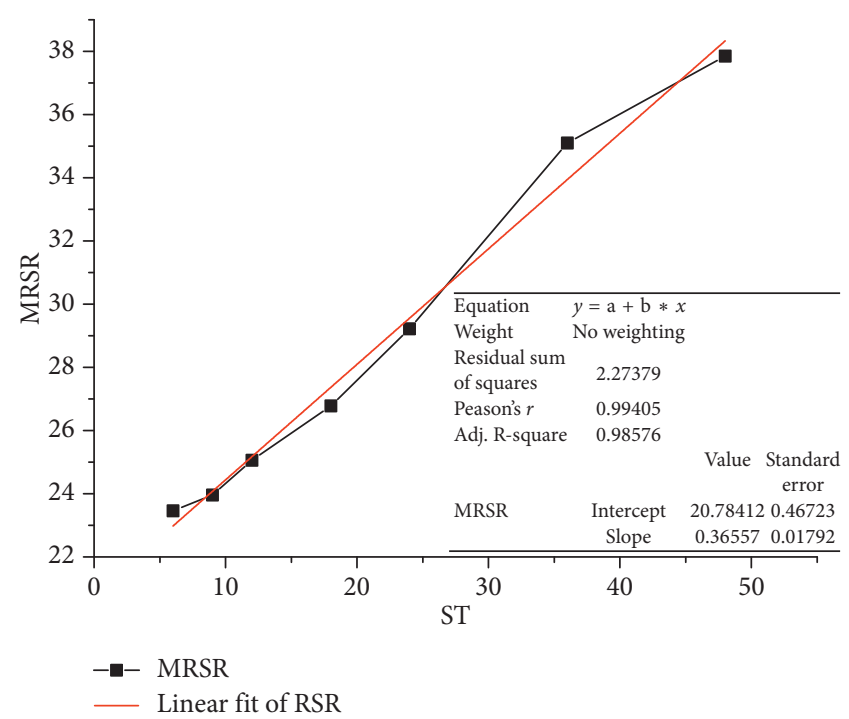

FIgURe 13: The relationship between MRSR and ST.

changing with ST can be obtained, such as the maximum factor of safety (MFOS), buried depth (BD), and rock thickness (RT) as shown in Figure 14.

By analyzing the relationship of BD and RT with ST, linear fitting could be used for prediction as shown in Formulas (13) and (14). The $R$-square is 0.9932 and 0.9714 , respectively, which prove the validity of the equation. The two equations can be easily used to predict $\mathrm{BD}$ and RT with maximum FOS under different ST. Therefore, the equations can guide the determination of buried depth for metro station.

$$
\begin{aligned}
& \mathrm{BD}=1.942 * \mathrm{ST}+6.984, \\
& \mathrm{RT}=0.941 * \mathrm{ST}+6.983 .
\end{aligned}
$$

\section{Three Zones and Discussion}

If taking $\mathrm{FOS}=1$ as the critical point, the upper and lower limit of self-stability zone can be obtained, which is named the $\mathrm{E}$ zone in this paper. The zone above and below the $\mathrm{E}$ zone is called $\mathrm{D}_{\mathrm{I}}$ and $\mathrm{D}_{\mathrm{II}}$ zone, respectively. By computation, the distribution map of three zones is shown in Figure 15.

From Figure 15, the dividing line for $\mathrm{D}_{\mathrm{I}}$ and $\mathrm{E}$ zone and the dividing line for $\mathrm{E}$ and $\mathrm{D}_{\mathrm{II}}$ zone can be calculated by Formulas (15) and (16), respectively:

$$
\begin{aligned}
& y_{1}=1.0598 x^{0.992}, \\
& y_{2}=580 .
\end{aligned}
$$

The characteristic of three zones for tunneling is universal. The characteristic is usually caused by the relationship between geostatic stress and self-supporting capacity of stratum. Geostatic stress linearly increases with $\mathrm{BD}$ as shown in Figure 16. For the zone near the ground surface, stratum is weak and discontinuous. Tunnel cannot be self-stable even though the geostatic stress is low. As $\mathrm{BD}$ increases, the 


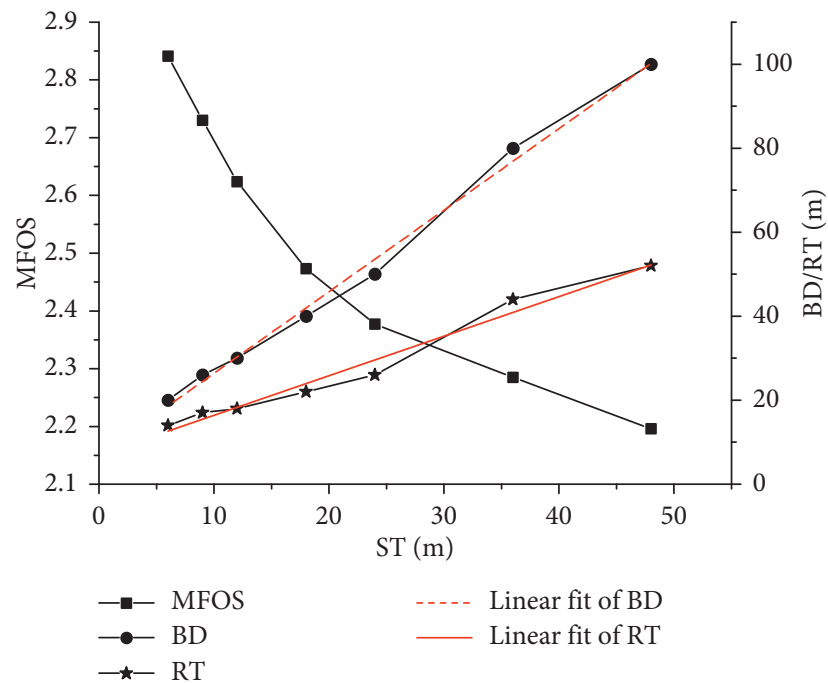

FIGURE 14: The relationship between MFOS, BD, RT, and ST.

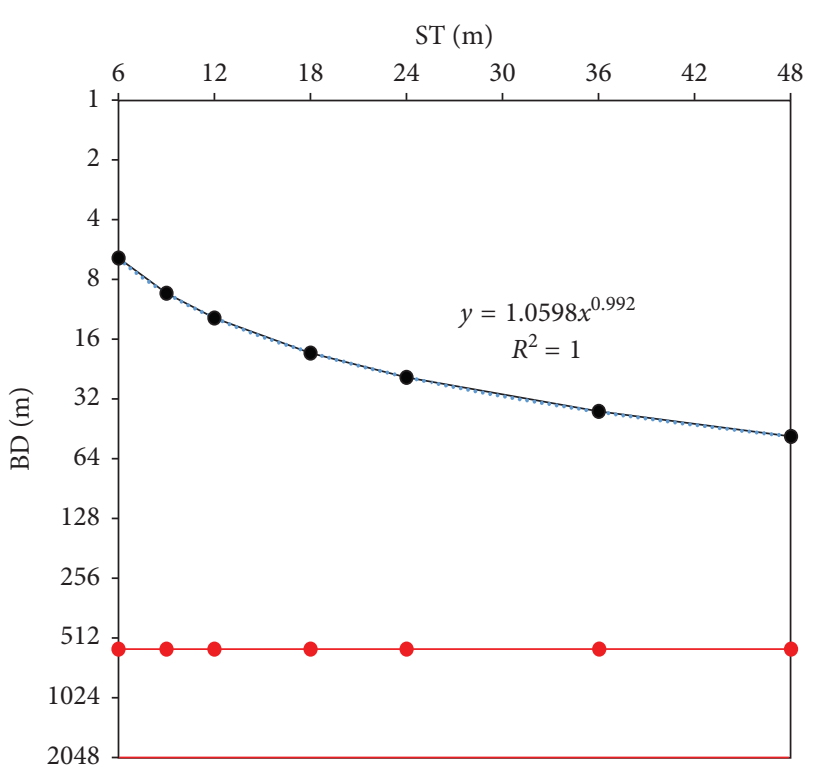

FIgURE 15: The distribution map of the three zones.

geologic exogenic action will be weak. The self-stability of tunnel will increase quickly and resist the influence of geostatic stress. However, as $\mathrm{BD}$ increases further, the geostatic stress enlarges as well, but the strength and selfsupporting capacity of stratum does not increase. The peak capacity of surrounding rock will be reached, and the construction will be difficult as well.

Two variations may occur in the practical engineering: first, $\mathrm{E}$ zone does not exist; second, $\mathrm{D}_{\mathrm{I}}$ does not exist. For the first one, when ST is large, tunnel gets into the geostatic stress leading zone before the self-supporting capacity of surrounding rock increases quickly. For the second one, the bedrock is outcropping whose self-supporting capacity is high, and $\mathrm{D}_{\mathrm{I}}$ zone will be disappear.

When designing, the metro station is better to be in the $\mathrm{E}$ zone, which can improve safety, accelerate schedule, and

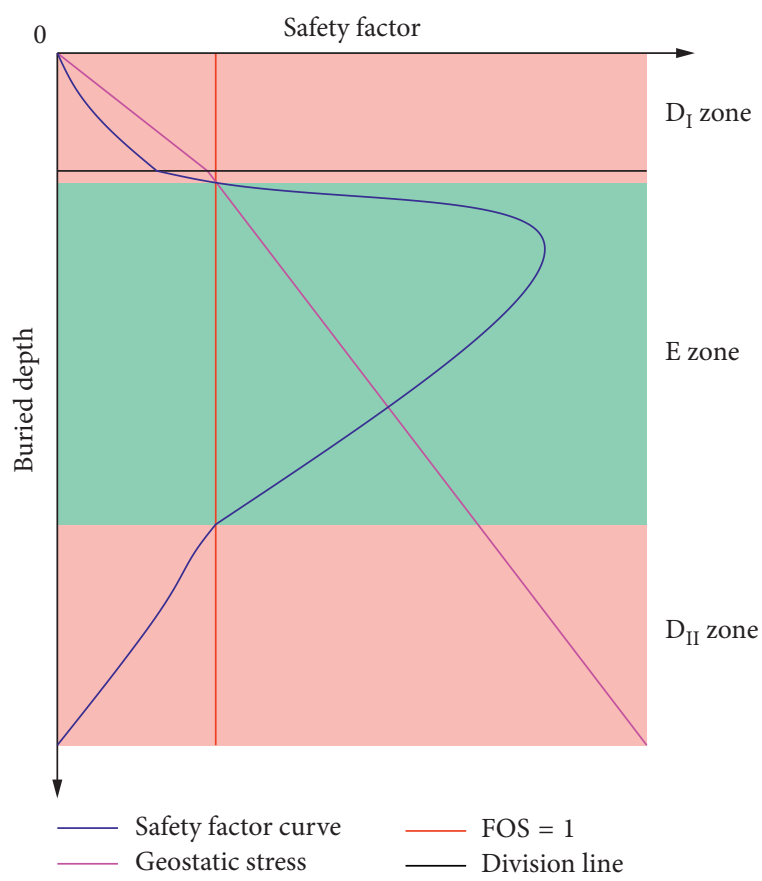

FIgURE 16: The relationship of three zones and stress.

decrease cost. Based on the work of geological exploration, the reasonable buried depth can be determined according to the geological results and subway characteristic. When the metro station is constructed in the $\mathrm{E}$ zone, the project will be more secure and cost less in the view of the project's total life cycles.

\section{Typical Projects}

The total length of Qingdao metro line 3 is $25.925 \mathrm{~km}$. The entire line is underground. There are 22 metro stations and the maximum, the minimum, and the average distance between stations are 1558.70 meters, 759 meters, and 1159.81 meters, respectively. Based on the geological data from thousand drillings, the distribution map of stratum along line 3 can be obtained by analyzing the geological parameters as shown in Figure 17.

\subsection{Relationship of Buried Depth and Geological Condition.} Three types of geological zones could be distinguished for the metro station. When the metro station is totally in soil zone, it belongs to the soil type. When the metro station is totally in rock stratum, it belongs to the rock type. When the metro station is partly in the soil layer and partly in the rock stratum, it belongs to the interface type. For different buried depth, the probability of the three types for Qingdao metro line 3 is shown in Figure 18. As the buried depth increases, the probability of the soil type reduces slightly, the probability of rock type increases fast, and the probability of the interface type decreases rapidly. When the buried depth is over $20 \mathrm{~m}$, the probability of the rock type is more than $90 \%$. However, the buried depth of line 3 is between 4.7 meters and 19.8 meters. Based on the actual engineering survey, the 


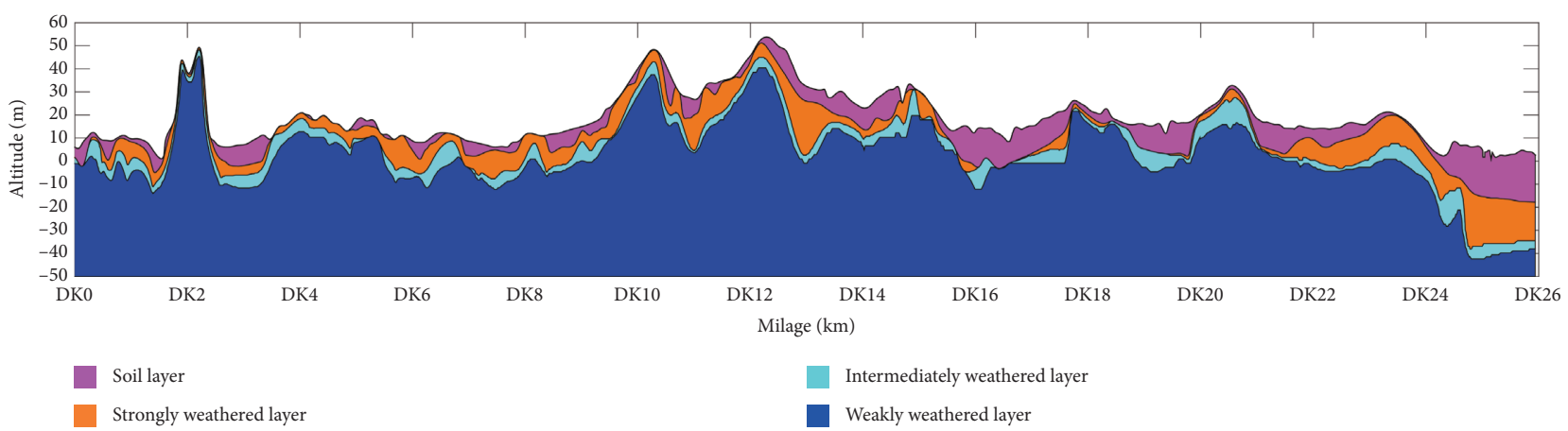

FIgURE 17: The geological distribution of metro line 3 in Qingdao.

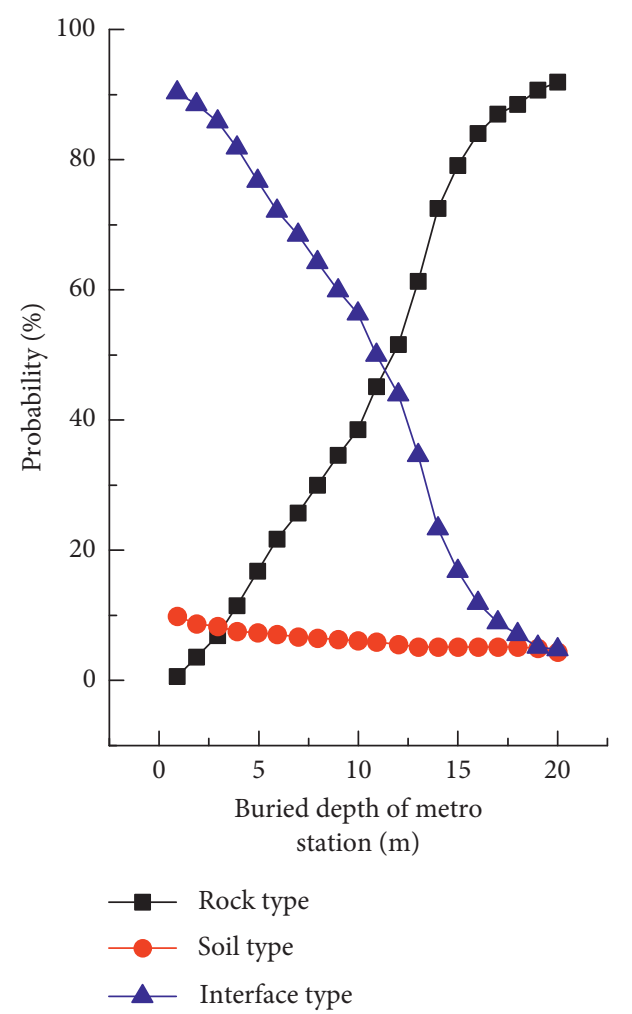

FIGURE 18: The probability of the three types of metro station for Qingdao metro line 3.

metro station is either the interface one or the rock one. Two metro stations have been chosen as the typical cases to analyze the distribution of zones, which belongs to the rock type and the interface type, respectively.

5.2. Junfeng Road Station. The mileage range of Junfeng road station is $\mathrm{K} 20+803.295 \sim \mathrm{K} 20+982.795$, and the length is 179.5 meters, which is an underground double-layer island station. The supporting structure is composite lining, with the width of 20.8 meters and the height of 18.4 meters. The CRD method has been adopted in original design. The buried depth of vault is between 7.3 meters and 15.4 meters. Junfeng road station is a typical case for the rock type, and the station stays in slightly weathered granite as shown in
Figure 19. Using Formula (15), the distribution of $\mathrm{D}_{\mathrm{I}}$ and $\mathrm{E}$ zone of this station can be obtained as shown in Figure 20.

From Figure 20, Junfeng road station is in the E zone. It should be easy to construct. The time of the contract is from June 1st, 2010 to September 30th, 2012, which sums to 852 days. The actual duration is 1671 days for the construction. The delay time is 819 days, which is caused by the surrounding environment, such as the house removal and the traffic regulation, but not the project itself. Since the station belongs to the rock type, the CRD method has been changed to the CD method with more efficiency. The decision is made based upon the monitoring data. The layout of monitoring points and the settlement values changing with time have been shown in Figures 21 and 22. The settlement value is much less than the alarm value $(0.03 \mathrm{~m})$, and the influence to the surrounding environment and the structure-self is neglectable. Altogether, because Junfeng road station is built in the E zone, the project not only saves time but also improves the safety.

5.3. Jiangxi Road Station. The start and end mileage of Jiangxi road station is $\mathrm{K} 8+358.491$ and $\mathrm{K} 8+605.491$, respectively. The length of the station is 247 meters. The supporting structure of this station is composite lining. The width of the station is 20.6 meters, and the height of the station is 14.5 meters. The buried depth of vault is in the range of $4.70 \sim 10.4$ meters. The station is constructed using the both side heading method.

Jiangxi road station is a typical case for the interface type. The upper part of the station is in strong-weathered granite, but the lower part is in the slightly weathered granite as shown in Figure 23. Using Formula (15), the distribution of $\mathrm{D}_{\mathrm{I}}$ and $\mathrm{E}$ zone of this station can be obtained as shown in Figure 24.

From Figure 24, Jiangxi road station is in the $\mathrm{D}_{\mathrm{I}}$ zone, which will cause trouble during the construction process. The contract time is from June 1st, 2010 to January 31th, 2013 and sums to 975 days. During the actual construction, the time is 2127 days. And the prolonged time is 1152 days, which is about 3 years. One reason is that the excavation method is slow for the complex procedure. Another reason is that the displacement is too large which affects the safety of surrounding environment. The layout of measure points for ground surface settlement is shown in Figure 25. The 


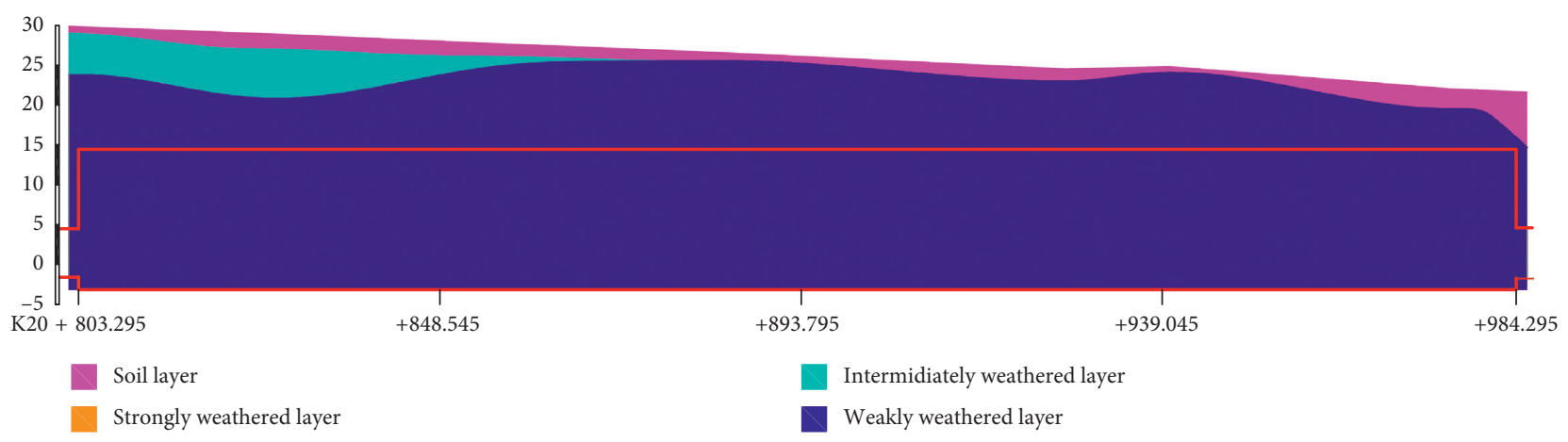

FIGURE 19: The geological condition for Junfeng road station.

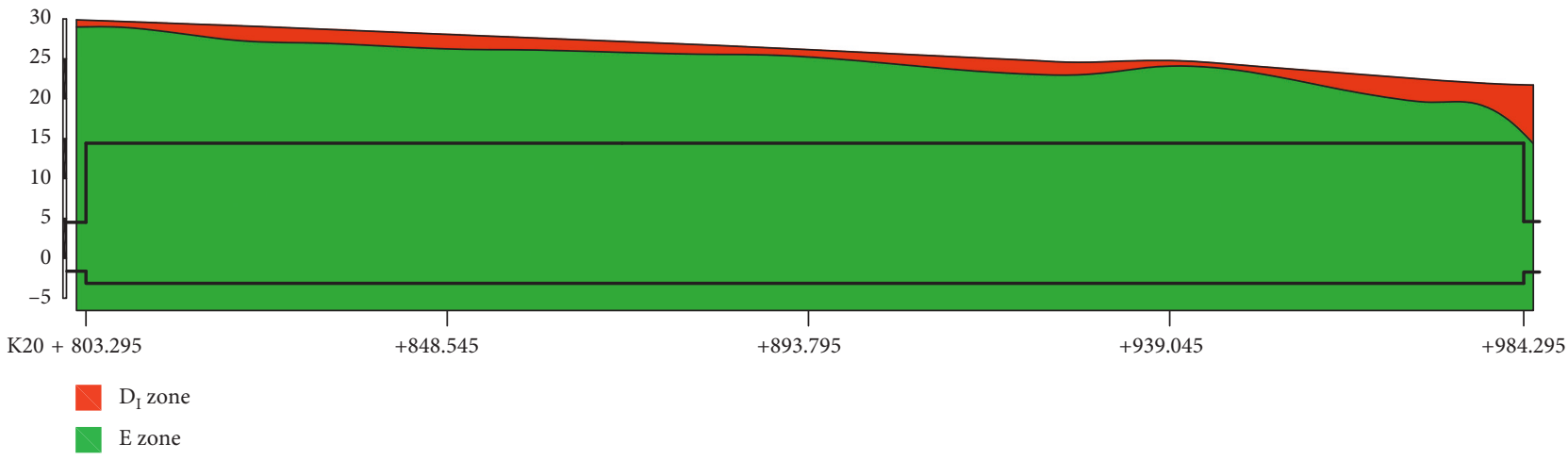

FIgURE 20: The distribution of $\mathrm{D}_{\mathrm{I}}$ and $\mathrm{E}$ zone of Junfeng road station.

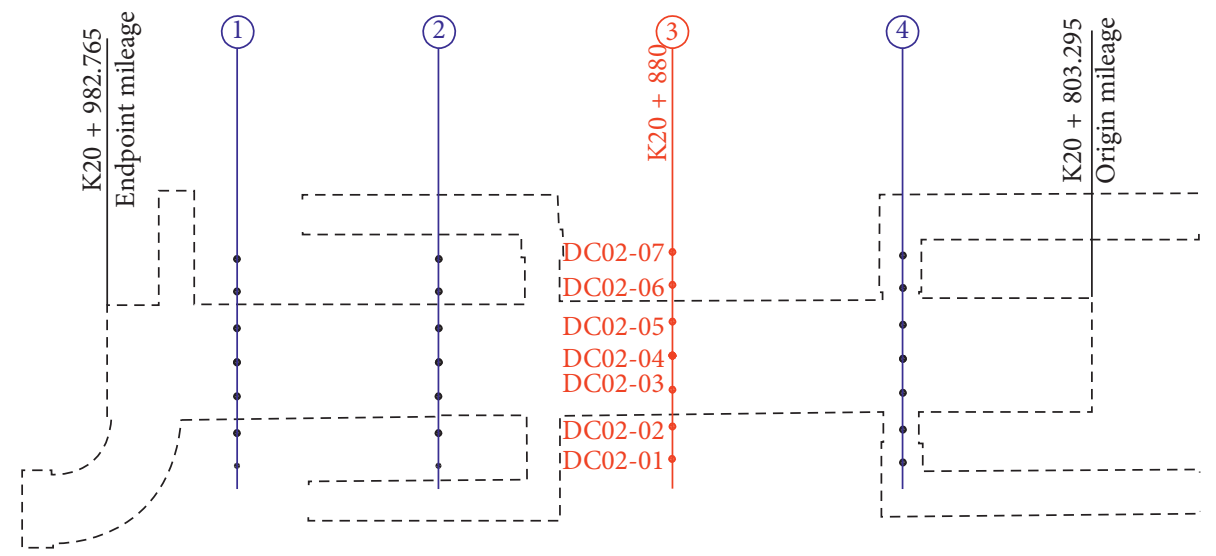

FIgURE 21: The layout of monitoring points for Junfeng road station.

settlement value of typical points for the $\mathrm{K} 8+414$ cross section is shown in Figure 26. The displacement is larger than the alarm value $(0.03 \mathrm{~m})$, and the maximum value is 0.063 meters. The settlement has caused various degree of influence to the ground traffic. Altogether, the time delay and the harmful deformation are determined by the geological condition because Jiangxi road station is not built in the $\mathrm{E}$ zone but in the $\mathrm{D}_{\mathrm{I}}$ zone, which belongs to the interface type. By the research results of Figure 24, the buried depth of this station should be deeper than 5 meters. At this depth, the tunnel will be in E zone, and the difficulty during the construction and the cost will decrease dramatically.

The practice for the two projects show that building the station in $\mathrm{E}$ zone is much better than that in $\mathrm{D}_{\mathrm{I}}$ zone, due to the monitoring data and the construction time. For the E zone, the deterioration probability and severity of surrounding rock are much less than those of the $\mathrm{D}_{\mathrm{I}}$ zone. The work effort and cost for maintenance will be less. Therefore, when determining the buried depth of subway in a city with similar geological condition, the geological condition should be considered as the 


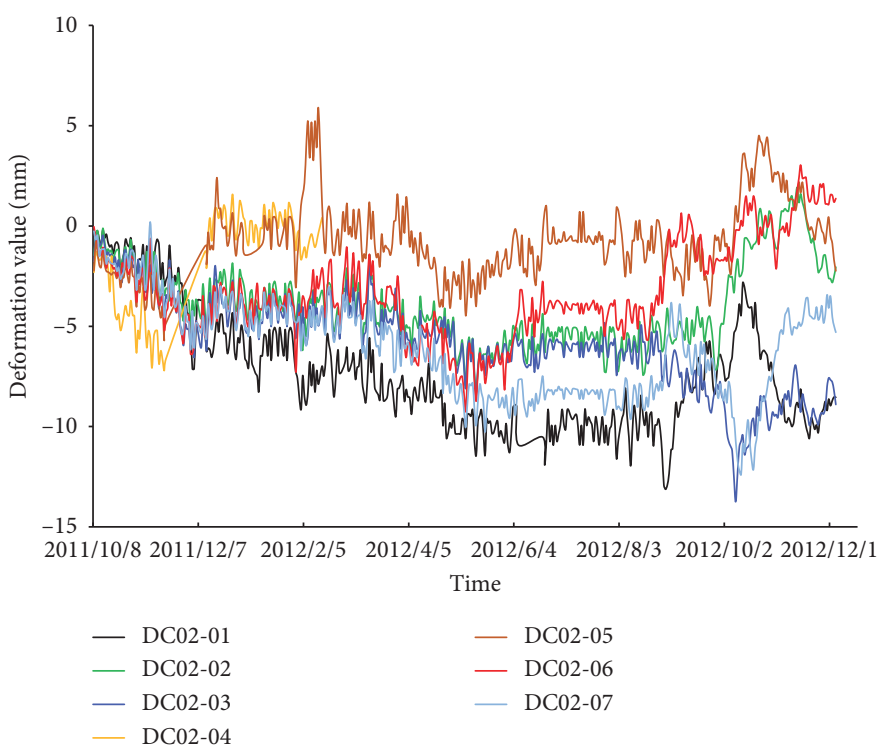

FIgURE 22: The settlement values for some monitoring points.

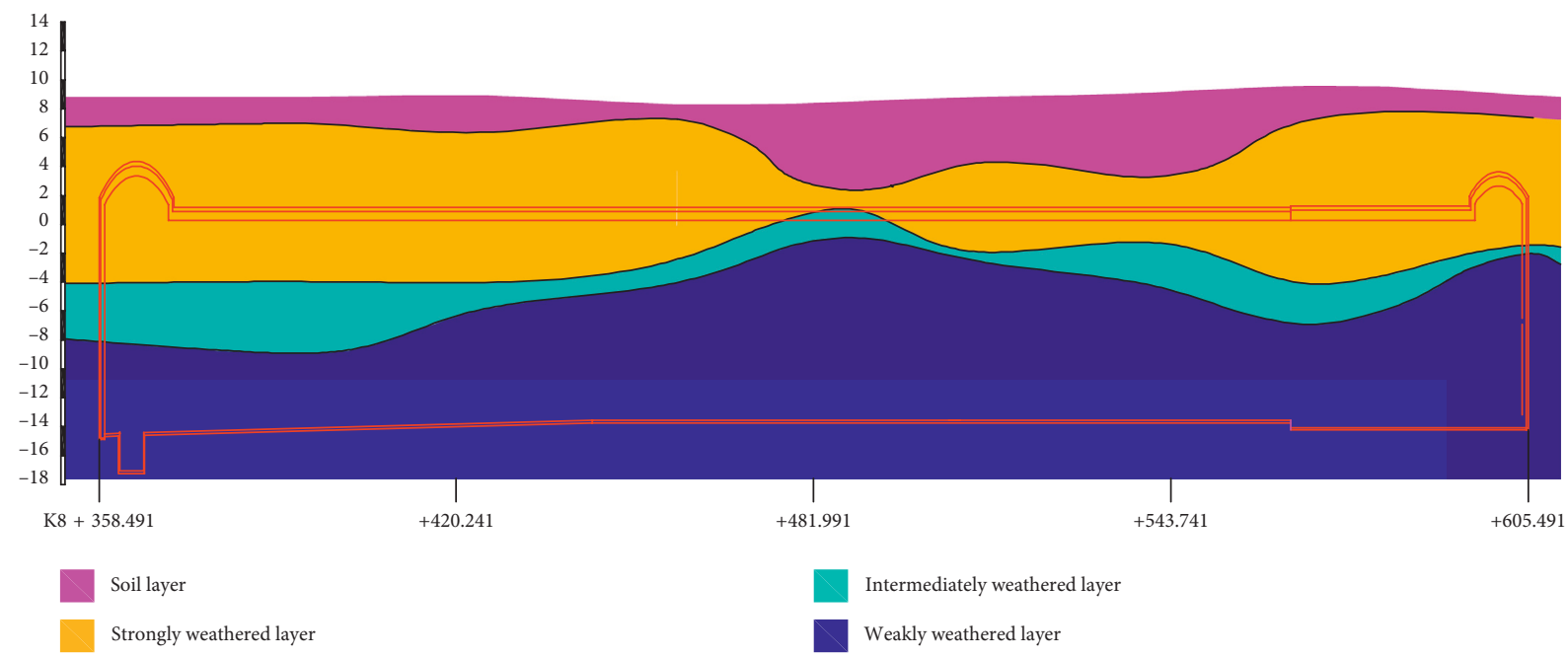

FIgURE 23: The geological condition for Jiangxi road station.

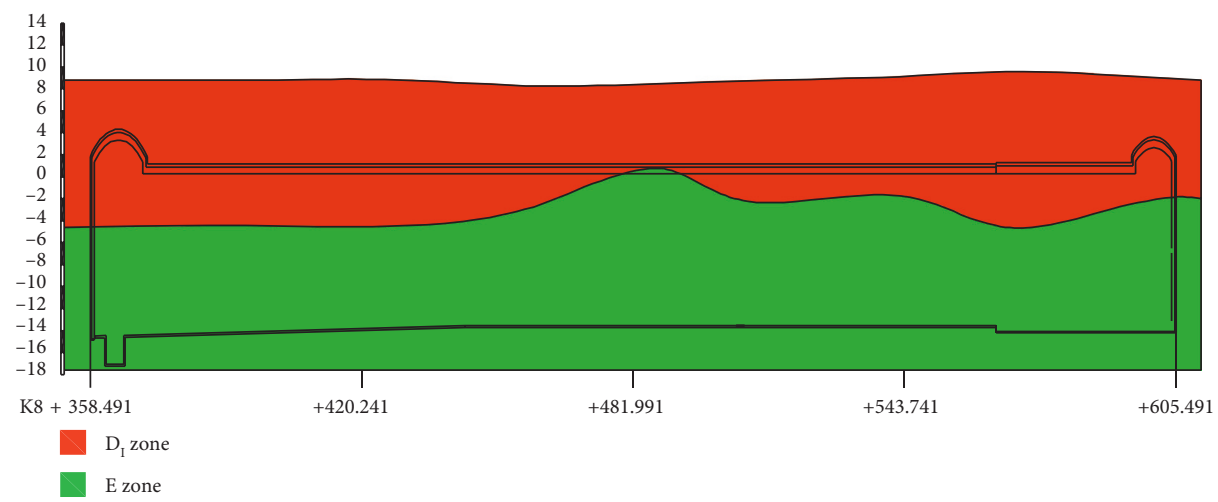

FIgURE 24: The distribution of $\mathrm{D}_{\mathrm{I}}$ and $\mathrm{E}$ zone of Jiangxi road station. 


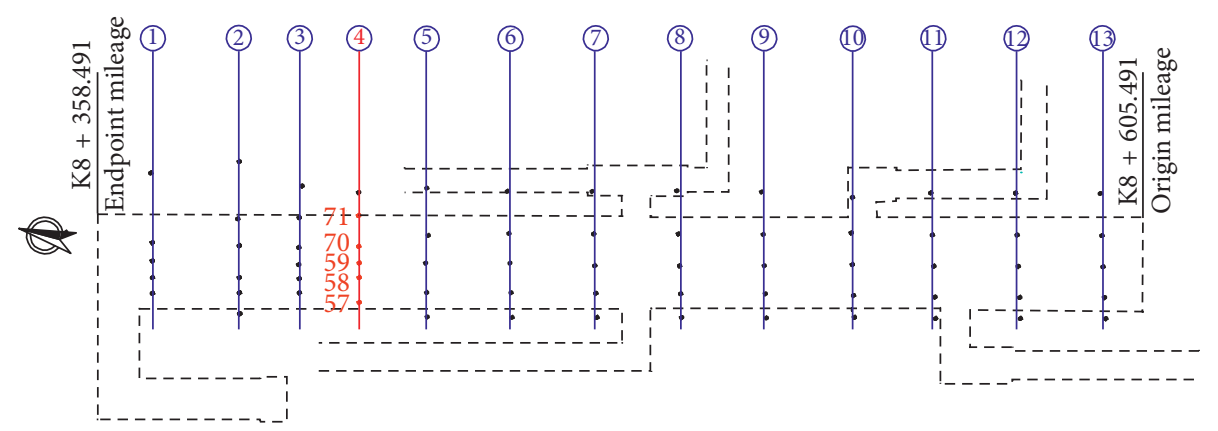

FIgURE 25: The layout of measure points for ground surface settlement.

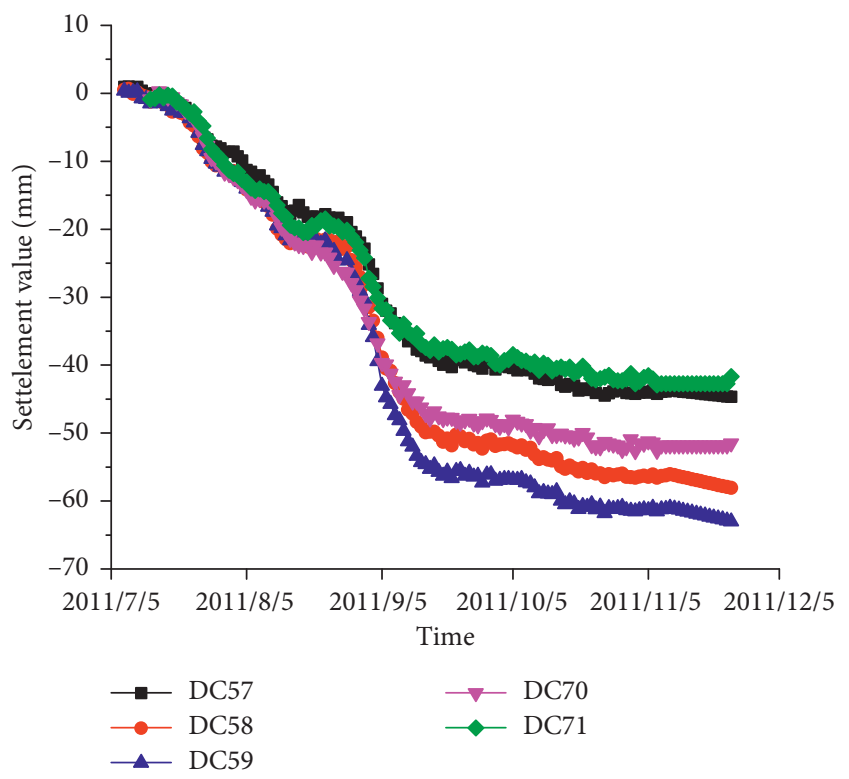

Figure 26: The settlement value of typical points for the $\mathrm{K} 8+414$ cross section.

most important factor, and designing the subway into E zone will increase the safety and decrease the cost.

\section{Conclusions}

(1) In the upper-soft and lower-hard stratum, FOS of the metro station with different buried depth has been obtained by the SRM, of which the rule is clear and the results are reasonable.

(2) As the BD of metro station increases in the uppersoft and lower-hard stratum, the change of FOS can be divided into three parts: slowly changed part, rapidly increased part, and gradually decreased part.

(3) ST has a significant effect on FOS. When the metro station belongs to the soil or interface type, FOS will be less than 1 and is in the slowly changed part. When the tunnel enters into the rock stratum totally, FOS will increase quickly and reach the maximum value. When the BD increases continuously, the FOS will decrease gradually and equals to 1 when $\mathrm{BD}$ is 580 meters.
(4) In the upper-soft and lower-hard stratum, the effect of upper soil stratum to tunnel can be treated as a load. If the BD is shallow, the influence of load is distinct, and as the $\mathrm{BD}$ increases, the effect decreases. If the $\mathrm{BD}$ is over 200 meters, the variation of soil thickness has little influence to the FOS of metro station.

(5) Taking FOS $=1$ as the critical value, along the stratum depth direction, the distribution of three zones ( $\mathrm{D}_{\mathrm{I}}, \mathrm{E}$, and $\mathrm{D}_{\mathrm{II}}$ zone) has been obtained, which is universal. For the dividing line of $\mathrm{D}_{\mathrm{I}}$ and $\mathrm{E}$ zone, the relationship between $\mathrm{BD}$, LRCT, MRSR, and ST has been obtained and has been verified by practical projects, such as Jiangxi road and Junfeng road station of subway line 3 in Qingdao. For the dividing line of $\mathrm{E}$ and $\mathrm{D}_{\mathrm{II}}$ zone, it is invariant for the study case. Since there is no deep tunnel in Qingdao city, the DII zone has not been verified in this paper and it will be validated in the future.

\section{Data Availability}

The data used to support the findings of this study are available from the corresponding author upon request.

\section{Conflicts of Interest}

The authors declare that they have no conflicts of interest.

\section{Acknowledgments}

This study was funded by the National Natural Science Foundation of China (nos. 51678495 and 51578463).

\section{References}

[1] K. G. Sun, Y. F. Gong, W. P. Xu, W. G. Qiu, and H. C. Zhou, "Research on the dismantling temporary support of metro station with shallow-depth subsurface-excavated and largespan," Journal of Railway Engineering Society, vol. 33, no. 7, pp. 94-100, 2016.

[2] L. F. Tian, "Support system optimization of double-side wall excavation method for subway station tunnel under complicated condition," Railway Standard Design, vol. 60, no. 7, pp. 130-133, 2016.

[3] C. Y. Song and W. G. He, "Structural design of the stacked loaded arch of large-span tunnels in upper-soft lower-hard 
rock stratum," Modern Tunnelling Technology, vol. 55, no. 1, pp. 17-26, 2018.

[4] J. H. Atkinson and A. M. Cairncross, "Collapse of a shallowtunnel in a Mohr Coulomb material," in Proceedings of Symposium on the Role of Plasticity in Soil Mechanics, A. C. Palmer, Ed., Cambridge, UK, September 1973.

[5] R. J. Mair, Centrifugal Modelling of tunnel Construction in Soft Clay, Ph.D. thesis, University of Cambridge, Cambridge, UK, 1979.

[6] E. H. Davis, M. J. Gunn, R. J. Mair, and H. N. Seneviratine, "The stability of shallow tunnels and underground openings in cohesive material," Geotechnique, vol. 30, no. 4, pp. 397$416,1980$.

[7] H. B. Muhlhaus, "Lower bound solutions for circular tunnels in two and three dimensions," Rock Mechanics and Rock Engineering, vol. 18, no. 1, pp. 37-52, 1985.

[8] E. Leca and L. Dormieux, "Upper and lower bound solutions for the face stability of shallow circular tunnels in frictional material,” Geotechnique, vol. 40, no. 4, pp. 581-606, 1990.

[9] M. Fraldi and F. Guarracino, "Analytical solutions for collapse mechanisms in tunnels with arbitrary cross sections," International Journal of Solids and Structures, vol. 47, no. 2, pp. 216-223, 2010.

[10] R. K. Rowe and G. J. Kack, "A theoretical examination of the settlements induced by tunneling four case histories," $\mathrm{Ca}$ nadian Geotechnical Journal, vol. 20, no. 2, pp. 299-314, 1983.

[11] N. C. Koutsabeloulis and D. V. Griffiths, "Numerical modeling of the trap door problem," Geotechnique, vol. 39, no. 1, pp. 77-89, 1989.

[12] R. F. Azevedo, A. B. Parreira, and J. G. Zornberg, "Numerical analysis of a tunnel in residual soils," Journal of Geotechnical and Geoenvironmental Engineering, vol. 128, no. 3, pp. 227236, 2002.

[13] K. G. Sun, F. Lu, and W. G. Qiu, "Back analysis of the incremental displacement of a large-span bored metro station," Modern Tunnelling Technology, vol. 52, no. 2, pp. 120-127, 2015.

[14] O. C. Zienkiewicz, C. Humpheson, and R. W. Lewis, "Associated and non-associated visco-plasticity and plasticity in soil mechanics," Geotechnique, vol. 25, no. 4, pp. 671-689, 1975.

[15] T. Matsui and K. C. San, "Finite element slope stability analysis by shear strength reduction technique," Soils and Foundations, vol. 32, no. 1, pp. 59-70, 1992.

[16] H. Zheng, L. G. Tham, and D. Liu, "On two definitions of the factor of safety commonly used in the finite element slope stability analysis," Computers and Geotechnics, vol. 33, no. 3, pp. 188-195, 2006.

[17] H. Zheng, G. H. Sun, and D. F. Liu, "A practical procedure for searching critical slip surfaces of slopes based on the strength reduction technique," Computers and Geotechnics, vol. 36, no. 1-2, pp. 1-5, 2009.

[18] H. Lin and J. Y. Chen, "Back analysis method of homogeneous slope at critical state," KSCE Journal of Civil Engineering, vol. 21, no. 3, pp. 670-675, 2017.

[19] S. Y. Liu, L. T. Shao, and H. J. Li, "Slope stability analysis using the limit equilibrium method and two finite element methods," Computers and Geotechnics, vol. 63, pp. 291-298, 2015.

[20] W. M. Yao, B. Hu, C. Ma, and H. B. Zhang, "Applicability research on the dip slope with interbeddings of weak and strong rocks using strength reduction method," Geotechnical and Geological Engineering, vol. 35, no. 3, pp. 1111-1118, 2017.

[21] J. Z. Ma, J. Zhang, H. W. Huang, L. L. Zhang, and J. S. Huang, "Identification of representative slip surface for reliability analysis of soil slopes based on shear strength reduction," Computers and Geothechnics, vol. 85, pp. 199-206, 2017.

[22] S. W. Sloan and A. Assadi, "Stability of shallow tunnels in softground," in Proceedings of Wroth Memorial Symposium on Predictive Soil Mechanics, G. T. Holsby and A. N. Schofield, Eds., pp. 644-663, Thomas Telford, Oxford, UK, July 1993.

[23] A. V. Lyamin and S. W. Sloan, "Stability of a plane strain circular tunnel in a cohesive frictional soil," in Proceedings of the J. R. Booker Memorial Symposium, pp. 139-153, A.A. Balkema, Rotterdam, Netherlands, 2000.

[24] L. M. Zhang, Y. R. Zheng, Z. Q. Wang, and J. X. Wang, "Application of strength reduction finite element method to road tunnels," Rock and Soil Mechanics, vol. 28, no. 1, pp. 97-106, 2007.

[25] Y. R. Zheng, C. Y. Qiu, H. Zhang, and Q. Y. Wang, "Exploration of Stability analysis methods for surrounding rocks of soil tunnel," Chinese Journal of Rock Mechanics and Engineering, vol. 27, no. 10, pp. 1968-1980, 2008.

[26] Y. R. Zheng, "Development and application of numerical limit analysis for geological materials," Chinese Journal of Rock Mechanics and engineering, vol. 31, no. 7, pp. 1297-1316, 2012.

[27] Y. L. Zhao, Y. X. Wang, W. J. Wang, W. Wan, and J. Z. Tang, "Modeling of non-linear rheological behavior of hard rock using triaxial rheological experiment," International Journal of Rock Mechanics and Mining Sciences, vol. 93, pp. 66-75, 2017.

[28] Z. W. Wang, C. S. Qiao, and C. Y. Song, "Calculation method of relaxation pressure of shallow large span tunnel in up-soft/ low-hard rock stratum," Rock and Soil Mechanics, vol. 35, no. 8, pp. 2342-2352, 2014.

[29] X. D. Wang, S. H. Zhou, J. P. Chi, and X. F. Wu, "Study on shallow-buried tunnel's thickness-span ratio in upper-soft lower-hard ground," Chinese Journal of Underground Space and Engineering, vol. 7, no. 4, pp. 700-705, 2011.

[30] D. P. Kanungo, A. Pain, and S. Sharma, "Finite element modeling approach to assess the stability of debris and rock slope: a case study from the Indian Himalayas," Natural Hazards, vol. 69, no. 1, pp. 1-24, 2013.

[31] D. V. Griffiths and P. A. Lane, "Slope stability analysis by finite elements," Geotechnique, vol. 49, no. 3, pp. 387-403, 1999.

[32] E. M. Dawson, W. H. Roth, and A. Drescher, "Slope stability analysis by strength reduction," Geotechnique, vol. 49, no. 6, pp. 835-840, 1999. 


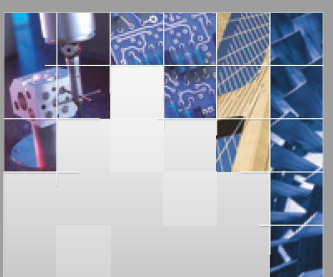

\section{Enfincering}
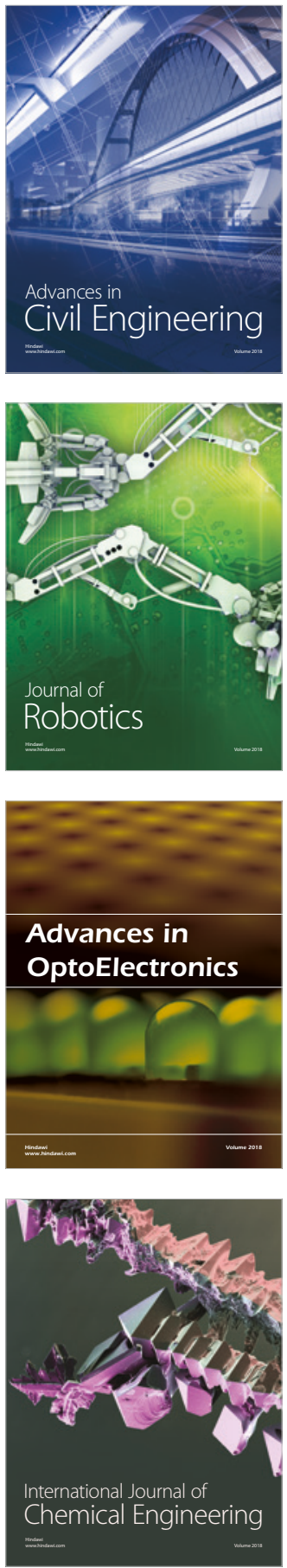

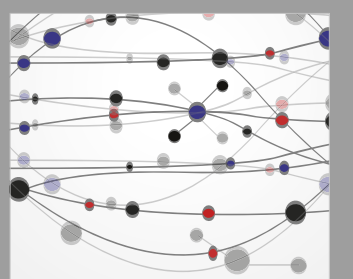

\section{Rotating \\ Machinery}

The Scientific World Journal

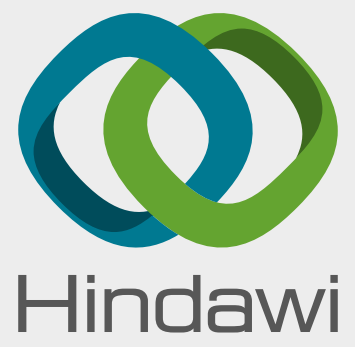

Submit your manuscripts at

www.hindawi.com
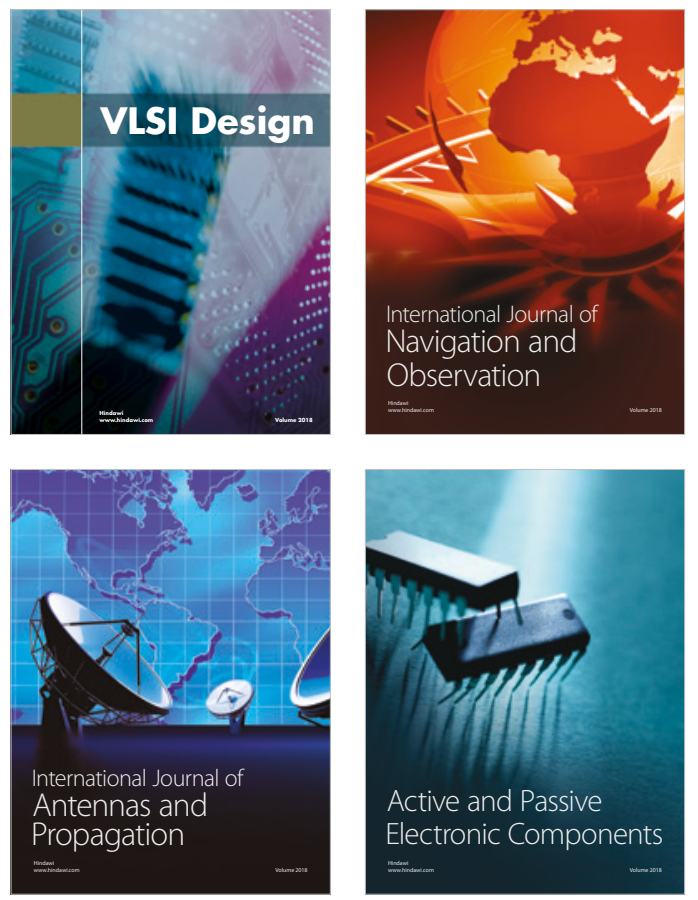
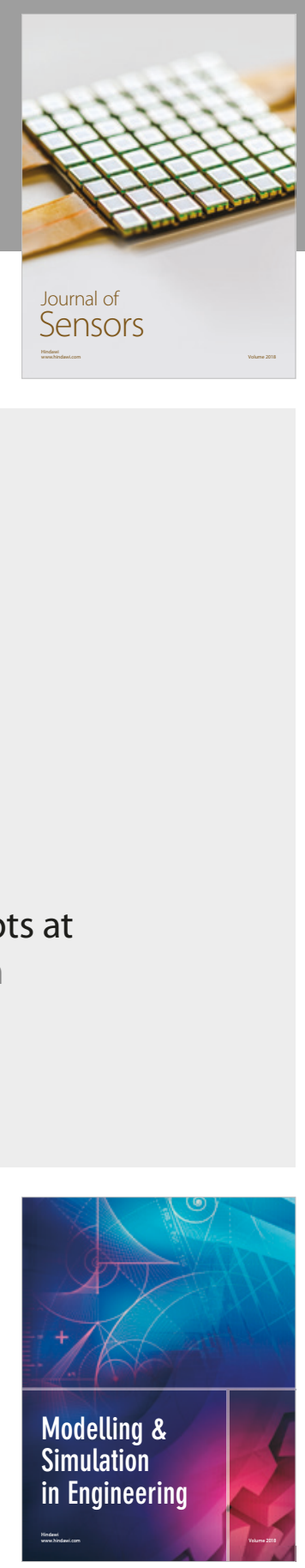

\section{Advances \\ Multimedia}
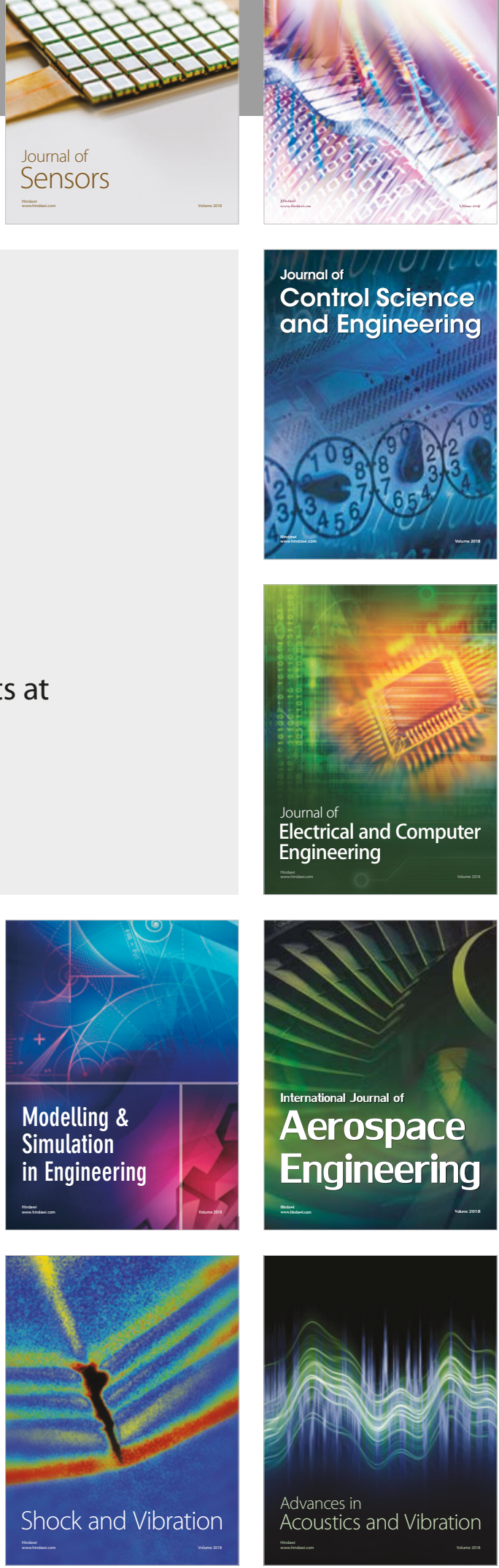